\title{
Nationalliberalismus in der Weimarer Republik
}

\author{
Die württembergische Landesorganisation der Deutschen Volkspartei (DVP) \\ 1919 bis 1933
}

Von Hans Peter Müller

Während die Geschichte der DVP im Deutschen Reich gut erforscht ist ${ }^{1}$, existiert keine Darstellung über die Partei in Württemberg ${ }^{2}$, wie überhaupt die Landesverbände in der Forschung bisher weitgehend ignoriert wurden. Zudem gibt es für Württemberg auch keine befriedigende Gesamtdarstellung der Weimarer Republik - nur deren Endphase wurde ausführlich behandelt ${ }^{3}$. Offenbar ist diese stiefmütterliche Behandlung auf die Tatsache zurückzuführen, dass die DVP in Württemberg nur über „eine sehr begrenzte Anhängerschaft“ verfügte ${ }^{4}$ und im Landtag nie Fraktionsstatus erreichte. Dennoch spielten ihre wenigen Abgeordneten, mitunter als „Zünglein an der Waage“, eine durchaus konstruktive und letztlich staatstragende Rolle. Der Wahlkreisverband - so die parteiamtliche Bezeichnung - konnte in der Reichspolitik, wo er bis 1932 nur durch einen Abgeordneten vertreten war,

${ }^{1}$ Vgl. als wohl umfassendste neue Darstellung Ludwig Richter, Die Deutsche Volkspartei 1918-1933, Düsseldorf 2002 mit umfangreichen Quellen- und Literaturangaben. Allerdings kommen bei Richter die Landesverbände nur sporadisch vor. Dies gilt auch für die Darstellung der Frühphase durch Wolfgang Hartenstein, Die Anfänge der Deutschen Volkspartei 1918-1920, Düsseldorf 1962. Dort wird die Gründung in Württemberg mit einem Zitat aus einer Berliner Zeitung „behandelt“ (S. 93, Anm. 1) und ansonsten - mit einem gewissen Recht - von einer „Diaspora“ der Partei gesprochen (S. 217f.).

2 Die Abhandlung von Hans-Otto Rommel, Aufbau und Zusammenbruch der Demokratie in Württemberg, in: Die F.D.P./DVP in Baden-Württemberg und ihre Geschichte, hg. von Paul Rothmund/Erhard R. Wienn, Stuttgart u.a. 1979, S.131-164, legt ihren Schwerpunkt auf die DDP. Dies gilt auch für Klaus Heger, Die Deutsche Demokratische Partei in Württemberg und ihre Organisation, Leipzig 1927, S. 63-69.

3 Waldemar Besson, Württemberg und die deutsche Staatskrise 1928-1933. Eine Studie zur Auflösung der Weimarer Republik, Stuttgart 1959; Thomas Schnabel, Württemberg zwischen Weimar und Bonn 1928-1945/46, Stuttgart 1986. Auch hier kommt die DVP jedoch nur am Rande vor. Eine informative, aber nicht detaillierte Darstellung bietet Reinhold Weber, Kleine Geschichte der Länder Baden und Württemberg 1918-1945, Leinfelden-Echterdingen 2008.

${ }^{4}$ Besson (wie Anm. 3) S. 32. 
kaum Akzente setzen. Im Gegensatz zu zahlreichen Regionalgruppierungen stand er jedoch treu an der Seite Stresemanns. In der Endphase der Republik schloss er sogar in eigener Regie ein Wahlbündnis mit den Linksliberalen, ein Schritt, der im Sinne Stresemanns dem Niedergang des Liberalismus entgegenwirken sollte.

\section{Die verspätete Gründung der DVP in Württemberg}

Obwohl sich nach dem Ende des Kaiserreichs eine Einigung von Links- und Nationalliberalismus abzuzeichnen schien, ist dieses Vorhaben gescheitert. Während Gustav Stresemann, der vormalige Führer der nationalliberalen Reichstagsfraktion, sich dem naheliegenden Gedanken eines liberalen Zusammengehens zunächst nicht verschloss, sah er sich aus den Reihen der sich formierenden Deutschen Demokratischen Partei (DDP) als Anhänger annexionistischer Kriegsziele und eines Siegfriedens diffamiert und schließlich ausgeschaltet. Dies veranlasste ihn, zusammen mit dem rechten Flügel seiner Partei am 15.12.1918 die DVP zu gründen, die sich als Erbin des Nationalliberalismus sah und fortan mit der ,linken DDP in Dauerfehde lag 5 .

Die hier nur skizzierte Entwicklung in Berlin, die für die junge Republik nur als negativ bezeichnet werden kann, fand im parteipolitischen Umgruppierungsprozess in Württemberg - jedenfalls was die liberalen Parteien betraf - zunächst keine Parallele. Vielmehr schien hier das Ende der Deutschen Partei (DP), der Nationalliberalen des Kaiserreichs, besiegelt zu sein. Es kam zunächst nicht zur Gründung eines Landesverbandes der DVP, vielmehr wurden die Mitglieder der DP sozusagen zerrieben: Ihr wohl größter Teil wurde quasi handstreichartig in die DDP übergeführt, ein anderer, vornehmlich der rechte Flügel, schloss sich der neugegründeten und sich liberal gebärdenden Bürgerpartei $a^{6}{ }^{6}$. Schließlich hielten sich auch Ehemalige zunächst ganz außerhalb.

Es war erstaunlich, dass ausgerechnet der nationalliberale Parteiführer, Landtags- und Reichstagsabgeordnete Johannes Hieber zum Liquidator seiner Partei wurde. Obwohl das linksliberale Parteiblatt, der „Beobachter“, für eine „sorgfältige Auslese" unter den in die DDP aufzunehmenden Nationalliberalen plädierte”, warb Hieber, wie Stresemann ein Mann mit , annexionistischer Vergangenheit ${ }^{{ }^{8}}$,

${ }^{5}$ Vgl. dazu mit Quellenangaben und weiterführender Literatur insbesondere RichteR, Die Deutsche Volkspartei (wie Anm. 1) S.31-45.

${ }^{6}$ Vgl. zur Bürgerpartei, die bald zum Landesverband der Deutschnationalen Volkspartei (DNVP) mutierte, Hans Peter Müller, Die Bürgerpartei/Deutschnationale Volkspartei (DNVP) in Württemberg 1918-1933, in: ZWLG 61 (2002) S. 375-433 und Reinhold Weber, Bürgerpartei und Bauernbund in Württemberg. Konservative Parteien im Kaiserreich und in Weimar, Düsseldorf 2004.

7 Gottlob Egelhaaf, Lebenserinnerungen, bearb. von Adolf Rapp, Stuttgart 1960, S. 138.

${ }^{8}$ Er war Mitglied der Alldeutschen und der Vaterlandspartei gewesen. Vgl. Hans Peter 
für den Eintritt seiner Parteifreunde in die neue Partei, ohne dabei auf nennenswerten Widerstand zu stoßen. Nach Egelhaaf ließ sich „die Masse [...] überschreiben [...], bestimmt durch das Zutrauen, das sie Hieber [...] entgegenbrachten“9.

Der mit dieser Entwicklung unzufriedene Egelhaaf, ein Veteran der DP, wollte nicht „untätig“ bleiben und wandte sich an die Bürgerpartei. Nachdem ihm dort erklärt wurde, „die Nationalliberalen könnten in ihr nationalliberal bleiben“, schloss er sich im Dezember der Neugründung an. Eine ihm angebotene Kandidatur zur Nationalversammlung lehnte er aus Altersgründen ab, beteiligte sich jedoch im Januar 1919 „mit der Feder und als Redner“ am Wahlkampf und wurde Mitglied des Landesausschusses. Obwohl er bekannte, mit seinen „Grundsätze(n) niemals irgendwie behindert“ worden zu sein, hatte er keine „neue(n) Freunde“ gefunden und war in der Bürgerpartei „nicht so ganz warm“ geworden ${ }^{10}$.

Inzwischen war der Stuttgarter Rechnungsrat Georg Schmidgall, der die Fusion mit der DDP als nationalliberale „Selbstendwürdigung“ empfand ${ }^{11}$ und auch nicht in die Bürgerpartei eintrat, aktiv geworden. Nach seinem Aufruf im „Merkur“ kam es am 21. Februar 1919 zur Gründung einer Stuttgarter Ortsgruppe der DVP, in der er den Vorsitz übernahm. Mit Gesinnungsfreunden besuchte er den Jenaer Parteitag der DVP im April, während „bürgerparteilich Elemente“ versuchten, die Ortsgruppe für sich zu gewinnen ${ }^{12}$. Am 25. April hielt die Ortsgruppe eine Versammlung ab, an der auch Dr. Curtius als Vertreter der badischen Landesorganisation und Geheimrat Sachs aus Berlin als Mitglied des Reichsausschusses teilnahmen. Schmidgall berichtete dort vom Parteitag und betonte, die DVP sei entschlossen, auch in Württemberg ibren Anteil am politischen Leben zu beanspruchen. Man habe inzwischen der Bürgerpartei erklärt, als Kompromiß-Gebilde besitze sie auf Dauer keine Existenzberechtigung und hellsichtig hinzugefügt, sie werde sich zwangsläufig zum Landesverband der DNVP wandeln. Dann müsse ihre Minderheit zur DVP stoßen. Man wünsche, dass dieser Prozess in schiedlich-friedlichen Formen verlaufe und sich eine harmonische Nebeneinanderarbeit ergebe ${ }^{13}$. Schmid-

MüLler, Die Deutsche Vaterlandspartei in Württemberg 1917/18 und ihr Erbe. Besorgte Patrioten oder rechte Ideologen?, in: ZWLG 59 (2000) S. 217-245, hier S. 227.

9 EgelhaAf (wie Anm. 7), S. 139. Vorangegangen war diesem Prozess eine Vertreterversammlung der DP am 23.11.1918, bei der nur Egelhaaf und ein weiterer Parteifreund erfolglos widersprachen. Vgl. ebd., S.138f. - Der Einfluss Hiebers auf seine Parteifreunde schien immens gewesen zu sein. So berichtete Johannes Rath, die Tübinger Ortsgruppe der DP habe im November 1918 ein Zusammengehen mit den Demokraten abgelehnt. Dieser Beschluss sei dann nach Hiebers Entscheidung jedoch revidiert worden. Undatiertes Manuskript („An alle ehemaligen Angehörigen der Nationalliberalen Partei“) von Rath, Stadtarchiv Tübingen E 10/N 93/94.

10 Egelhaaf (wie Anm. 7) S. 140 f.

11 Georg Schmidgall, Die Wiederaufrichtung der Nationalliberalen Partei als Deutsche Volkspartei in Württemberg, Stuttgart 1920, S. 4.

12 Ebd., S. 8, 10 f. Stresemann hatte ihm im März mitgeteilt, dass man eine Verschmelzung mit der DNVP ablehne. Ebd., S. 12.

13 Schwäbischer Merkur Nr. 187 vom 26.4.1919. 
gall reklamierte so für sich, die „Anregung zur Wiederaufrichtung“ des Nationalliberalismus in Württemberg gegeben zu haben ${ }^{14}$.

Mittlerweile war mit Theodor Bickes aus Stuttgart ein weiterer Akteur aus der DP auf den Plan getreten. Er trat Ende Dezember mit Parteifreunden an die Bürgerpartei heran, um dort die Modalitäten eines Beitritts derjenigen Nationalliberalen zu besprechen, die den Anschluss an die DDP strikt ablehnten. Sowohl hinsichtlich der Kandidatenaufstellung zu den Wahlen im Januar als auch bezüglich der Kardinalfrage, wie sich die Bürgerpartei zu den Parteien im Reich stelle, wurde Einigung erzielt. Daraufhin erklärten sich die Nationalliberalen zum Beitritt in die Bürgerpartei bereit, allerdings unter dem ausdrücklichen Vorbebalt, dass dadurch ibre Zugehörigkeit zur Deutschen Volkspartei im Reich in keiner Weise berührt wird ${ }^{15}$. Bickes vollzog diesen Schritt dann im Februar 1919 - nach langer und reiflicher Ueberlegung ${ }^{16}$.

Seit März bemühte er sich dann um weitere Klärung. Im April besuchte er ebenfalls den DVP-Parteitag in Jena, wo es ihm jedoch nicht gelang, ein Gespräch mit Stresemann zu führen, mit dem er bereits korrespondiert hatte. Am 17.4. sandte er ein Schreiben an die Berliner Reichsgeschäftstelle, um die nicht einfachen württembergischen Verbältnisse zu schildern, über die man dort offenbar nicht ausreichend informiert sei. Dabei betonte er selbstbewusst, nach rund 20 Jahren führender Tätigkeit in der DP auch die derzeitige Situation genau zu kennen. Mit Gleichgesinnten, die den Schritt nach Links ablehnten, habe er die Entwicklung der DDP beobachtet, die offenbar mit riesigen Geldmitteln einen an Amerika erinnernden Feldzug inszenierte und mit der Warnung Hiebers vor der DVP operiert habe. Ohne eigene Finanzen sei man von der Idee abgekommen, eine eigene Ortsgruppe zu gründen, zudem habe die neugegründete Bürgerpartei sofort eine große Zugkraft ausgeübt. Sein Beitritt zu dieser sei mit dem Ziel erfolgt, die beigetretenen Tausende bisheriger Nationalliberaler [...] nicht schutzlos einer Partei zu überlassen, die nach seiner Einschätzung eines Tages zur DNVP stoßen könnte. Vielmehr habe man gehofft, die Bürgerpartei später in die DVP zu führen, zumal ganze Ortsgruppen [...] sich fast restlos aus ehemaligen Nationalliberalen zusammensetzen oder von solchen geleitet werden.

Dann habe jedoch die Gründung der Ortsgruppe durch Schmidgall alles verdorben. Diese habe allgemein Misstrauen erweckt und sei zu früh gekommen. Der Versuch einer Überleitung der Bürgerpartei oder ihrer ehemals nationalliberalen Mitglieder zur DVP sei so vereitelt worden. Bickes erhoffte eine baldige Klärung und stellte seinen Austritt bei der Bürgerpartei in Aussicht ${ }^{17}$.

14 Schmidgall (wie Anm. 11) S. 10.

15 Protokoll über die Besprechung vom 29.12.1918, Nachlass Hans Sachs, Stadtarchiv Crailsheim, N 16.

16 Bickes an die Reichsgeschäftsstelle der DVP, 17.4.1919, ebd.

17 Ebd. - Der von Bickes und Schmidgall hellsichtig erwartete Anschluss der Bürgerpar- 
Er erhielt von der Reichsgeschäftstelle die Antwort, die Parteileitung habe den Geheimen Regierungsrat Sachs - er war in Crailsheim aufgewachsen-, gebeten, die Fübrung in den weiteren Verbandlungen zu übernehmen ${ }^{18}$. Während nun Sachs Kontakte nach allen Seiten suchte - er war wenige Tage später wie erwähnt in Stuttgart -, beharrte Schmidgall auf seinen besonderen Verdiensten und reduzierte die Bemühungen von Bickes, die ihm jedenfalls teilweise bekannt waren, auf die lakonische Feststellung, dieser habe sich mit seinen Freunden „nach und nach“ der Partei angeschlossen ${ }^{19}$. Dagegen begrüßte er freudig, dass Anfang September Gottlob Egelhaaf zur sich formierenden Partei stieß ${ }^{20}$.

Dieser hatte am 17. 9. im „Merkur“ einen Artikel „Meine Rückkehr zur nationalliberalen Partei“ veröffentlicht, der auch als Sonderdruck versandt wurde. Er betonte dort die Notwendigkeit einer „Mittelpartei“ und versprach, dieser „die letzte Kraft seines Alters“ zu widmen ${ }^{21}$. Damit war dann der zuvor durch unkoordiniertes und konkurrierendes Verhalten erschwerte Weg zur Formierung des Landesverbandes geebnet. Mit Anzeigen, die von der Bürgerpartei mit einem Gegenaufruf beantwortet wurden ${ }^{22}$, lud Egelhaaf namens eines vorbereitenden Ausschusses zum 26. und 27. September in die Stuttgarter Liederhalle ein.

Nach einer vielverheißende $(n)$ Versammlung mit etwa 700 bis 800 Besuchern am 26., vor denen der Reichstagsabgeordnete und Parteisenior Professor Kahl über Ziele und Programm der DVP gesprochen hatte ${ }^{23}$, fand am Folgetag die erste Vertreter-Versammlung und damit der eigentliche Gründungsakt der württembergischen Landesorganisation statt. Vor 92 Delegierten aus dem ganzen Lande hielt Sachs eine lange Rede, in der er einleitend von Württemberg, wo die Parteiorganisation am weitesten zurückliege, als einem Sorgenkind der DVP sprach. Dennoch erfüllten ihn die Hunderte von zum Teil begeisterten Anmeldungen aus allen Landesteilen mit Optimismus. Dieser sei auch dadurch berechtigt, dass man im Gegensatz zu früher eine wahre Volkspartei geworden sei, die die soziale Klassenversöhnung erstrebe. Diese Weichenstellung gehe auf Stresmann zurück, allerdings verdanke man die Entstehung nicht dessen Ehrgeiz, sondern dem norddeutschen Widerstand dagegen, sich ins geistige Schlepptau der Neuberliner kosmopolitisch-internationalen Demokratie nebmen zu lassen. Als Mittelpartei stehe man nun gegen die rechten Deutschnationalen und die linke DDP und betreibe die Reichs-Erneuerung.

tei an die DNVP erfolgte im Herbst 1920. Vgl. Müller, Die Bürgerpartei (wie Anm.6) S. 390 .

18 Schreiben vom 22.4.1919, Nachlass Hans Sachs (wie Anm. 15).

19 Schmidgall (wie Anm. 11) S. 13.

20 Ebd., S. 13 f.

${ }^{21}$ Egelhaaf (wie Anm. 7) S. 148.

${ }^{22}$ Vgl. dazu und zur Vorgeschichte auch Weber, Bürgerpartei (wie Anm. 6) S. $131 \mathrm{f}$.

23 Schwäbischer Merkur Nr. 449 vom 29.9.1919 (Morgenblatt). 
Auf ihn folgte Egelhaaf, der es als zwingendes Erfordernis bezeichnete, Württemberg auch parteiorganisch in den Rabmen der Reichspolitik einzufügen. Nach weiteren Rednern und einer anschließenden Aussprache, bei der etwa der badische Parteivorsitzende Curtius die bürgerparteilichen Führer als ausgesprochene Reaktionäre bezeichnete und Bickes anmerkte, dass ehemalige Nationalliberale, die einen Treueaufruf der Bürgerpartei unterzeichnet hätten, nie Mitglieder der DP gewesen seien. Schließlich wurde Egelhaaf einstimmig zum Landesvorsitzenden gewählt, während die übrigen Vorstandsämter vorläufig durch den Ausschuss der Stuttgarter Ortsgruppe wahrgenommen werden sollten ${ }^{24}$.

Am 29. September wurde u.a. Schmidgall, dem Egelhaaf wärmsten Dank für sein Wirken aussprach, in den Stuttgarter Ortsausschuss gewählt, an die Vereinsspitze trat Bickes. Nach der Besetzung weiterer Ämter dankte der vormalige Vorsitzende auch Sachs für seine Verdienste um die Nenaufrichtung der Partei ${ }^{25}$. Diese war, namentlich was die Errichtung von Ortsvereinen im Lande betraf, nicht leicht. Werbeversammlungen wurden u.a. durch Kohlemangel erschwert, dennoch entstanden seit Ende 1919 die ersten Lokalvereine wie etwa in Ulm, Aalen, Tübingen und Heilbronn ${ }^{26}$. Zudem litt der Landesverband unter Finanznöten ${ }^{27}$.

\section{Ideologie und politische Ziele - die Klientel der Partei}

Die auf dem Leipziger Parteitag im Oktober 1919 beschlossen „Grundsätze“ der DVP $^{28}$ bekannten sich zu liberalen Prinzipien und wiesen zahlreiche Ähnlichkeiten mit dem Programm der DDP auf. Gleichzeitig waren etwa im Bereich der Mittelstandspflege, der Stellung zum Handwerk, zur Landwirtschaft und zu den Angestellten und Arbeitern Gemeinsamkeiten mit den Deutschnationalen erkennbar. Dies gilt auch dort, wo die Nationalliberalen rückwärtsgewandt die Wiederberstellung der rubmvollen schwarz-weiß-roten Reichsfarben und das durch freien Entschluß des Volkes auf gesetzmäßigem Wege aufzurichtende Kaisertum forder$\operatorname{ten}^{29}$.

${ }^{24}$ Schwäbischer Merkur Nr. 449 vom 29.9.1919 (Abendblatt).

${ }^{25}$ Schwäbischer Merkur Nr. 452 vom 1.10.1919.

26 Egelhaaf (wie Anm. 7) S. $148 \mathrm{f}$.

27 Richter, Die Deutsche Volkspartei (wie Anm.1) S. 198 mit Anm. 20.

28 Abgedruckt bei Wolfgang Treue, Deutsche Parteiprogramme 1861-1954, Frankfurt/ Berlin 1954, S. 113-122.

29 Ebd., S. 114. Den Kaisergedanken relativierte Egelhaaf in seiner ersten größeren Landtagsrede: Angesichts anderer drängender Probleme wolle man dieses Ziel vorläufig nicht forcieren; das Volk könne später eine Entscheidung treffen. Verhandlungen des Landtags des freien Volksstaates Württemberg (fortan Landtag) vom 4.11.1920, S. 510-517. Vgl. auch Vaterlandsfreund Nr. 261 vom 6.11.1920. 1924 betonte er, man fördere weiterhin den monarchischen Gedanken, ziele aber keineswegs auf dessen gewaltsame Herstellung, Rede in Gaildorf, Kocherbote Gaildorf (fortan KB) Nr. 42 vom 19.2.1924.

Zeitschrift für Württembergische Landesgeschichte 74 (2015), S. 249-296.

(C) Kommission für geschichtliche Landeskunde in Baden-Württemberg und Württembergischer Geschichts- und Altertumsverein e.V.

ISSN 0044-3786 
Die DVP trat zwar für die Völkerversöhnung ein, präsentierte sich jedoch ganz dezidiert national. So forderte sie die Wiederherstellung der zertretenen Ebre des deutschen Volkes und die ibm gebübrende Achtung und Freibeit der nationalen und wirtschaftlichen Entwicklung ${ }^{30}$, schließlich wurde das Streben nach der frübere (n) Weltgeltung betont, zu dem die Rückgabe der Kolonien gehöre ${ }^{31}$.

Ein zentraler Begriff war für die Partei die zu erstrebende Volksgemeinschaft ${ }^{32}$, der auch in den Reden der Landespolitiker immer wiederkehrte ${ }^{33}$. Damit wollte man alle Zersetzungsbestrebungen, die sich gegen den nationalen Staat richteten, bekämpfen ${ }^{34}$. Zugleich wurde der Allgemeinplatz betont, im Christentum einen Grundpfeiler deutscher Kultur und deutschen Volkslebens zu sehen ${ }^{35}$.

Bemerkenswert war, dass sich die Partei dazu bekannte, dem auf Volk und Staat zersetzend wirkenden Einfluß des Großkapitals müsse scharf entgegengetreten werden $^{36}$. Dass die Praxis im Reich vielfach eine andere war, ist kaum zu bestreiten. Die einschlägige Literatur ist sich hier weitgehend einig, wie einige Beispiele belegen. Danach vertrat die DVP „die Interessen der Industrie“ ${ }^{37}$ oder wurde „zum Verfechter großindustrieller Interessen “38. Von marxistischer Seite hat man schließlich betont, dass in den „Führungsgremien und Parlamentsfraktionen [...] mehr unmittelbare Angehörige der Monopolbourgeoisie [...] saßen als in anderen bürgerlichen Parteien“39. Diese Befunde sind jedoch zu relativieren - sie gelten vor allem, allerdings nicht nur für die rheinisch-westfälischen Landesverbände mit ihrem überragenden Einfluss auf die Gesamtpartei ${ }^{40}$ - auf die Verhältnisse in Württemberg wird noch eingegangen.

30 Treue (wie Anm. 28) S. 114.

31 Ebd., S.120f. Unser Recht zu kolonialer Betätigung, verbunden mit dem Widerruf der Koloniallüge (Danach war Deutschland unfähig, Kolonien zu verwalten. HPM) beschwor 1924 auch Johannes Rath. Zusammen mit dem Widerruf der Kriegsschuldlïge waren dies für ihn Voraussetzungen für den Beitritt zum Völkerbund. Rede in Gaildorf, KB Nr. 272 vom 18.11.1924.

32 Treue (wie Anm. 28) S. 114.

33 Bickes sprach etwa von der Notwendigkeit einer nationale(n) Einheitsfront, eine( $r)$ Volksgemeinschaft als Mittel zur Rettung aus der deutschen Notlage, KB Nr.23 vom 29.1.1923.

34 Treue (wie Anm. 28) S. 115.

35 Ebd., S. 117.

36 Ebd., S. 116.

37 Walter Tormin, Die Weimarer Republik, Hannover 1973, S. 93.

38 Hans-Ulrich Wehler, Deutsche Gesellschaftsgeschichte, Bd. 4: Vom Beginn des Ersten Weltkriegs bis zur Gründung der beiden deutschen Staaten 1914-1949, München 2003, S. 356. Andere Autoren betonen mindestens ihren „gewichtigen schwerindustriellen Flügel“, Helmut Heiber, Die Republik von Weimar, München 1971, S. 35 oder ihre „industriefreundliche“ Haltung, Heinrich August Wink Ler, Weimar 1918-1933, München 1998, S. 185.

39 Wolfgang Ruge, Art. Deutsche Volkspartei (DVP) 1918-1933, in: Lexikon zur Parteiengeschichte, Bd.2, Leipzig 1984, S. 413 (Zitat)-446.

40 Vgl. dazu vor allem Richter, Die Deutsche Volkspartei (wie Anm. 1). 
Die hier skizzierte programmatische Ausrichtung der Partei soll nun durch Beispiele aus der frühen politischen Praxis ergänzt werden. Im Vorfeld der Landtagsund Reichstagswahlen vom 6. Juni 1920 hielt Gustav Stresemann am 20. Mai in Stuttgart eine lange Grundsatzrede vor etwa 3.000 Besuchern. Die vom „Merkur“ als machtvolle und geschlossene Kundgebung des liberalen Bürgertums gepriesenen Ausführungen wurden häufig durch stürmische(n) Beifall unterbrochen ${ }^{41}$. Der Parteiführer kritisierte die derzeitige Reichsregierung als ganz vom sozialdemokratischen Einfluß beherrscht und wandte sich gegen den Vorwurf, seine Partei sehe immer nur die Vergangenheit. Keineswegs sei sie unbedingter Lobredner des alten Systems, um dessen Reform sich die Nationalliberalen immer bemüht hätten. Allerdings gelte es, das Gute und Gesunde vom alten Deutschland mit gutem neuen Geist (zu) verbinden. Man habe die Evolution erhofft, während die Revolution ohne jegliches Konzept nur Zersetzung gebracht habe und ihr jeglicher Hauch einer nationalen Idee gefehlt habe. Die deutsche Fabne (sei) in den Schmutz gezogen worden; damit habe man die nationale Würde verletzt und zugleich ein Schuldbekenntnis abgelegt.

Stresemann sah das kaiserliche Deutschland wegen seiner Wirtschaftskraft von der Welt beneidet. Nun habe man feststellen müssen, dass die Hoffnungen auf den internationalen Gedanke(n) sich als Chimäre erwiesen habe. Während England saturiert sei, nachdem ihm Deutschland als Konkurrent auf dem Weltmarkt nicht mehr gefährlich werde, seien die großen Hoffnungen auf den amerikanischen Präsidenten Wilson trügerisch gewesen. Dieser sei ein Heuchler und ein verbissener Deutschenfeind.

Für die Innenpolitik konstatierte er, die Herstellung gesunder wirtschaftlicher Verbältnisse sei notwendiger gewesen als das Verfassungswerk, (dem die DVP ja nicht zugestimmt hatte). Er befürchtete ein Parteibentesystem, geprägt durch Parteimänner ohne Sachkompetenz. Der Wiederaufbau könne nur auf privatkapitalistischen Grundlagen erfolgen, die Wirtschaftsfübrung durch den Staat bzw. die Parteien sei abzulehnen. Vielmehr sei ein Wirtschaftsparlament, eine Kammer der Arbeit anzustreben, der auch durch ihre Organisationen entsandte Angestellte und Arbeiter angehören sollten.

Den Vorwurf, seine Partei sei Interessenvertreter der Schwerindustrie, konterte er mit dem Hinweis, dass auch die DDP von dieser unterstützt werde. Die ganze Industrie müsse im Interesse des Wiederaufbaus zusammensteben, die Produktion gesteigert, die Arbeitsintensität erhöht, der Achtstundentag dürfe nicht zum Dogma werden. Schließlich stimmte er auch optimistische Töne für die Zukunft an, forderte die Durchsetzung der Staatsautorität und den Schutz der Verfassung gegen Rechts und gegen Links, beschwor den Geist der Disziplin im Beamtentum,

${ }^{41}$ Die Rede erschien auch als Sonderdruck im Haller Tagblatt (fortan HT) Nr. 127 vom 3.6.1920. Daraus das Folgende.

Zeitschrift für Württembergische Landesgeschichte 74 (2015), S. 249-296.

(C) Kommission für geschichtliche Landeskunde in Baden-Württemberg und Württembergischer Geschichts- und Altertumsverein e.V.

ISSN 0044-3786 
eine wertorientierte Erziehung der Jugend und die Vaterlandsliebe, die gerade jetzt noch gesteigert werden müsse.

Überwiegend war die Rede noch ein Produkt des „alten“ Politikers; noch war er nicht jene Lichtgestalt, die er wenige Jahre später als nüchterner Realist werden sollte. Insgesamt schien er den Nerv der übergroßen Mehrheit seiner Zuhörer getroffen zu haben. Dazu gehörte allerdings auch, dass er gegen die Ostjuden - die galizischen Fremdlinge - polemisierte ${ }^{42}$.

Die württembergische DVP präsentierte sich 1920 hoffnungsvoll als große bürgerliche Partei der Zukunft, deren Mitgliedschaft inzwischen auf das Zehnfache gestiegen sei $^{43}$. In einer weiteren Wahlanzeige fasste sie ihren Standpunkt prägnant zusammen: Man sei national, nicht reaktionär wie die DNVP, liberal, nicht formaldemokratisch wie die DDP, sozial, nicht sozialistisch wie die Sozialdemokra$\mathrm{tie}^{44}$.

Das bisher Gesagte soll nun durch Aussagen führender württembergischer Nationalliberaler ergänzt werden. Theodor Bickes sprach Ende Januar 1923 über die Deutsche Not in Gaildorf, wo sich anschließend eine Ortsgruppe bildete. Er warb für die Volksgemeinschaft, die an die Stelle von Parteihader und Streit treten müsse und geißelte den Versailler Schandvertrag und damit das Ziel des französischen Erbfeindes einer Erdrosselung des Lebensnervs der deutschen Wirtschaft an Rhein und Ruhr und sah die Gefahr einer Loslösung des Südens vom Norden. Für ihn war es Wabnwitz, die Wiederkehr von Deutschlands früherem Glanz zu erwarten und eine Utopie, an die Versöhnung der Völker, an den Völkerbund oder an Präsident Wilson zu glauben. Die DVP sei bestrebt, eine Arbeitsgemeinschaft aller Parteien einschließlich der SPD zu erreichen - nur wenn sich Deutschland einig sei, könne man den Tag der Erlösung erwarten ${ }^{45}$.

Etwa ein Jahr später trat der Parteisenior Egelhaaf wiederum in Gaildorf vor eine außerordentlich gut besuchte Versammlung. Es war naheliegend, dass der Historiker sich intensiv mit der Vergangenheit beschäftigte: Unbesiegt sei Deutsch-

42 Martin Ulmer, Antisemitismus in Stuttgart 1871-1933, Berlin 2011, bescheinigte Stresemann, als Oppositionsführer einen „offenen moderaten Antisemitismus“ betrieben zu haben und sieht solche Tendenzen auch in der württembergischen DVP (S. 219). Stresemann bediente sicherlich da und dort antijüdische Klischees; die sogenannten Ostjuden waren auch manchen jüdischen Deutschen suspekt. Er wandte sich jedoch mehrfach auch gegen antisemitische Strömungen und war zudem - als angeblich mit einer Jüdin verheiratet selbst Angriffen ausgesetzt. Die Eltern seiner Gattin hatten sich vor deren Geburt taufen lassen. Vgl. Richter, Die Deutsche Volkspartei (wie Anm. 1) S. 82 mit Anm. 30, S. 257 f. mit Anm. 14. - Hans Sachs, für den dezidiert antisemitischen Deutschvölkischen Schutz- und Trutzbund sprechend, bezeichnete während der Stuttgarter Versammlung den Bolschewismus (als) eine jüdische Frage. Er verließ die Partei 1923 und legte seinen Sitz im württembergischen Landesvorstand nieder, KB Nr. 226 vom 27.9.1923.

43 Anzeige im Anschluss an den Sonderdruck der Stresemann-Rede, HT Nr. 127 vom 3.6.1920.

${ }^{44} \mathrm{~KB}$ Nr. 129 vom 5.6.1920.

45 KB Nr. 23 vom 29.1.1923. 
land im November 1918, betört von Wilsons Lüge zur Selbstentwaffnung geschritten, habe wehrlos einen Schandfrieden geerntet, urdeutsches Land $^{46}$, die Kolonien und die Flotte verloren und sei zur Leistung ungeheurer Summen verurteilt worden. Nach diesem zornigen Rückblick pries er die Leistungen des Reichskanzlers Stresemann, der als Idealist und Realpolitiker den aussichtslosen Rubrkampf beendet und mit seinem Kabinett die Stabilisierung der Währung bewirkt habe. Damit wurde deutlich, dass sich der Landesverband mit dem neuen Kurs des gewandelten Stresemann voll identifizierte.

So konnte der Redner Zuversicht für die Zukunft äußern: Europa erkenne allmählich, dass Deutschlands Gesundung unverzichtbar sei; ein ungeheurer Umschwung der europäischen Politik könne erwartet werden. Voraussetzung dazu bilde die Einigkeit der Deutschen ${ }^{47}$.

Ähnliche Akzente setzte auch Bickes in einem Vortrag vor der Haller Ortsgruppe der DVP. Er unterstrich zunächst, dass die Partei vor vier Jahren im Reich in schärfster Opposition zur Regierung gestanden habe. Diese Haltung sei gegen den Geist von Weimar sowie den der Revolution und die Unterzeichnung des Versailler Vertrages gerichtet gewesen. Zudem habe man vehement gegen die Kriegsschuldlüge gekämpft. Dennoch wolle man anerkennen, dass damals die Andersdenkenden im vaterländischen Interesse gehandelt hätten. Den Sozialdemokraten bescheinigte er, dass ihnen für die Befreiung vom Bolschewismus Dank gebühre.

Nach den Wahlen von 1920 habe sich die DVP jedoch zu positiver Mitarbeit im Staat entschieden und sich an den Regierungen Fehrenbach und Cuno beteiligt. Schließlich habe Stresemann, das Vaterland über die Partei stellend, die Regierung übernommen, wissend, dass dies der Partei nur Schaden zufügen werde. Bickes sprach von der Tragik des Führers, der zunächst vehement für den Ruhrkampf eingetreten sei, diesen jedoch als aussichtslos einstellen musste. Das Fazit des Stresemann voll unterstützenden Redners ging dahin, dass dieser Schritt keinen Sieg Frankreichs darstelle, habe doch das Sachverständigen-Gutachten zu den deutschen Reparationen - die Vorstufe des Dawes-Planes - letztlich ein vernichtendes Urteil über Versailles gebracht. Insofern gelte es, dem Gutachten kein starres Nein entgegenzusetzen. Deutschland sei gezwungen, durch Opfer seine Freiheit zurückzugewinnen. Schließlich lobte er die Einführung der Rentenmark als größte antimarxistische Tat des Kabinetts Stresemann.

Bickes setzte sich dann mit der die Volksgemeinschaft hintertreibenden politischen Rechten auseinander, kritisierte den Münchener Hitler-Putsch und sah die völkische Bewegung als gegen den Mittelstand gerichtet. Für diesen forderte er eine günstigere Steuerpolitik und wollte in der Aufwertungsfrage mehr Gerechtigkeit für Witwen und Waisen um dann den Beamten für ihre Opfer zu danken. Abschließend konstatierte er, man sei seit Kriegsende doch einen kleinen Schritt vorwärts

46 Vgl. auch seinen Aufsatz „Rettung für das Memelland“, KB Nr. 45 vom 23.2.1923.

47 KB Nr. 42 vom 19.2.1924. 
gekommen und betonte wie zuvor Egelhaaf eine bessere Stimmung zu Gunsten Deutschlands. Dennoch prognostizierte er für die kommenden Jahre noch einen große (n) Leidensweg ${ }^{48}$.

Die hier zuletzt behandelten Reden beleuchten die Zustimmung der Württemberger zu Stresemann. Während Bickes zunächst noch die Ressentiments des Parteiführers am Anfang der Republik spiegelte, identifizierte er sich 1924 wie Egelhaaf uneingeschränkt mit dem neuen Kurs, der staatstragenden Wende, die die Stresemannjabre der Republik (Golo Mann) einleitete. Diese Haltung blieb bis zum Tode Stresemanns 1929 sozusagen das reichspolitische Credo der württembergischen DVP. Ihr Landesverband war eine Bastion des Parteiführers, dem sie immer wieder unwandelbare Trene bekundeten ${ }^{49}$. Seiner Politik wie seinem rhetorischen Talent zollten sie Anerkennung und Bewunderung. So lobte etwa Johannes Rath die formvollendete Sprache und die gewandte Dialektik und betonte zugleich bedauernd, dass Frau Sorge [...] kein seltener Gast des Außenministers sei. Rath meinte, die Lösung des Reparationsproblems sei geradezu zum Lebenselement geworden, obwohl er eine moralische Verpflichtung zu deutschen Reparationen nicht anerkenne. Es sei Stresemanns Ziel, das Reich aus den heutigen Verhältnissen zu lösen und er glaube fest an dessen Wideraufrichtung ${ }^{50}$.

$$
* * *
$$

Hier soll nochmals auf das großkapitalistische Image der DVP geblickt werden, das schon 1932 auch für die Reichspartei in Frage gestellt wurde. Mit dem Etikett „Partei der Schlotbarone“ sei „nicht entfernt die politische Praxis der Volkspartei zu erklären, noch umfassend ihr historischer Ort zu treffen ${ }^{\text {"51 }}$. Auch Gottlob Egelhaaf, wohl ebenfalls auf die Gesamtpartei zielend, hat das Verdikt „Partei der Schwerindustrie“ mit seinem Befund einer „sozialen Partei“ gekontert. Er fügte hinzu, dass seit 1925 „alle Schwerindustriellen“ vornehmlich bei den Deutschnationalen, aber auch beim Zentrum und der DDP standen ${ }^{52}$. Mag dieses Urteil auch pro domo erfolgt sein, so belegt die württembergische Praxis doch ganz eindeutig, dass hier der Landesverband einen mittelständisch und sozial orientierten Kurs verfolgte. Dies geht zunächst schon daraus hervor, dass ihm keine Großunterneh-

48 HT Nr. 98 vom 26.4.1924.

49 So etwa eine Resolution des Landesparteitages vom April 1926, KB Nr.90 vom 20.4.1926.

50 „Dr. Stresemann, Ein Stimmungsbild ...“, KB Nr. 143 vom 20.6.1924.

51 Sigmund Neumann, Deutsche Volkspartei, in: Die Parteien der Weimarer Republik, Stuttgart 1965, S. 54-61, hier S. 55 (erstmals erschienen 1932). - Die Studie von Lothar DöHN (Politik und Interesse. Die Interessenstruktur der Deutschen Volkspartei, Meisenheim am Glan 1970) führt hier nicht weiter, da die Landesverbände dort kaum vorkommen.

52 Egelhaaf (wie Anm. 7) S. 165. Auch Rath wies den Vorwurf einer schwerindustriellen Partei am 26.1.1928 im Landtag zurück (S. 4675-4678). Vgl. auch Staatsanzeiger für Württemberg (fortan StAnz) Nr. 23 vom 28.1.1928. 
mer wie etwa Stinnes angehörten, die vor allem aber nicht nur, wie erwähnt, die Partei im Rheinland und in Westfalen prägten und sich immer wieder gegen Stresemann und den linken Parteiflügel stellten ${ }^{53}$. Die in der Haller Bickes-Rede von 1924 betonten sozialen und mittelsständischen Aspekte waren keine Rhetorik, sondern Ausdruck politischen Strebens. Ein Aufruf zur zweiten Reichstagswahl 1924 forderte eine geordnete Wirtschaft mit gleichem Recht und Schutz für alle Stände und plädierte für eine gerechte Steuer- und Aufwertungspolitik sowie weitgehendste Fürsorge für alle Kriegsopfer. Gezielt warb man auch um und für die eigene Klientel: Das Berufsbeamtentum solle gegen das Eindringen bloßer Parteigünstlinge geschützt werden und eine ausreichende Besoldung erhalten, Angestellte und Freiberufler als Angehörige des Mittelstandes gefördert, schließlich Arbeiter nicht nur Fürsorge erfahren, sondern zur Mitarbeit auf allen Gebieten herangezogen und zur Qualifizierung ermuntert werden ${ }^{54}$.

Ähnliche Akzente setzte auch der Aufruf zu den Landtagswahlen 1928, der den soziale (n) Ausgleich durch Schutz der wirtschaftlich Schwachen propagierte. Zum Wohnungswesen wurde ein angemessener Mieterschutz und die Förderung des privaten Wobnungsbaus gefordert, Kleinrentner ${ }^{55}$, Kriegsbeschädigte und Hinterbliebene müssten ausreichend versorgt, der gewerbliche und kaufmännische Mittelstand durch die Einschränkung des Hausierbandels geschützt, Kleinbetriebe steuerlich entlastet werden. Auch Forderungen im Sinne der Beamten wurden erneut bekräftigt ${ }^{56}$.

Die DVP gründete zur Verfolgung mittelständisch-sozialer Bestrebungen entsprechende Arbeitsgemeinschaften, die natürlich auch der besseren Verankerung in der Wählerschaft dienen sollten. Im Dezember 1926 konstituierte sich ihr „Arbeiter- und Angestellten-Ausschuss“, dabei wurde die bobe Bedeutung der nationalen Gewerkschaftsbewegung betont ${ }^{57}$. 1929 konstatierte man dort die Unzufriedenheit der Arbeitnehmer mit der DNVP und dem Zentrum und leitete daraus die Verpflichtung ab, die auch eine Berliner Tagung bestätigt habe, den aufstrebenden Arbeitnebmerschichten den gebübrenden Platz in der Partei einzuräumen und ibren berechtigten Forderungen Rechnung zu tragen ${ }^{58}$. Im März 1927 kam es im Rah-

53 Vgl. dazu Richter, Die Deutsche Volkspartei (wie Anm. 1).

${ }^{54}$ Das in Stuttgart gedruckte Flugblatt „Achtung!“, Stadtarchiv Stuttgart, Nachlass Kimmich/Schmalzried, 14/4 (z. T. Fettdruck oder gesperrt).

${ }^{55} \mathrm{Zu}$ deren Gunsten bat der Landesausschuss Anfang Februar 1928 die Reichstagsfraktion, sich um die baldige Verabschiedung des Rentnerversorgungsgesetzes zu bemühen. Der Reichstag dürfe nicht auseinandergehen, ohne seiner Pflicht gegenüber den durch die Inflation so schwer geschädigten Teilen des deutschen Volkes genügt zu baben, StAnz Nr. 32 vom 8.2.1928. - Rath kritisierte am 9.5.1931 im Landtag (S. 3229f.), man habe in den vergangenen Jahren für alles Mittel gehabt, nur nicht für die Kleinrentner.

56 Wahlnachrichten der Deutschen Volkspartei (fortan Wahlnachrichten), Nr.2 vom 14.5.1928.

57 KB Nr. 287 vom 8.12.1926.

58 StAnz Nr. 36 vom 12.2.1929. 
men einer Mittelstandstagung zur Gründung eines Ausschusses für Handwerk und Gewerbe. Dessen Vorsitzender wurde der Esslinger Glaserobermeister Mayer ${ }^{59}$, der seine Partei von 1928-1932 im Landtag vertrat und 1924 und 1933 für den Reichstag kandidierte. Zudem war er kommunalpolitisch tätig ${ }^{60}$ und darf als Beispiel für die Vernetzung der DVP gelten. Schließlich entstand auch ein Landesbeamtenausschuss, der jede Zurücksetzung des Berufsbeamtentums bekämpfen wollte $^{61}$. Ferner existierten ein kommunalpolitischer Ausschuss ${ }^{62}$ sowie eine Frauengruppe unter Lisbeth Heyd, die von 1926 bis 1928 dem Landtag angehörte. Sie konstatierte 1928 ein weitgehendes Verständnis der Partei für Frauenforderungen ${ }^{63}$. Dazu gehörte etwa, dass 1928 Frau Oberst Port aus Ulm u.a. zur Stellvertreterin des Landesvorsitzenden gewählt wurde ${ }^{64}$.

Die Verankerung der württembergischen Nationalliberalen im Mittelstand wird schließlich auch durch ihre Kandidatenauswahl deutlich. Ein Aufruf zur Gemeinderatswahl für Groß-Stuttgart forderte etwa Gerechtigkeit in Stenerfragen und Schutz der Schwachen. Der hochwichtige Mittelstand als Hüter staatlicher und sozialer Ordnung dürfe nicht noch weiter herabgedrückt werden. Polemisiert wurde gegen einzelne schnell reich gewordene Volksgenossen und insgesamt der Geist der Gemeinschaft beschworen. Präsentiert wurden 30 Bewerber, darunter drei Frauen. Zwölf einschließlich der Lehrer waren höhere oder mittlere Beamte, acht fielen in die Kategorie der selbständigen Gewerbetreibenden und Kaufleute, je zwei waren Ingenieure und Fabrikanten. Schließlich kandidierten ein Angestellter, ein Steuersyndikus, ein Veterinär und ein Chefredakteur ${ }^{65}$.

Als weiteres Beispiel seien die 13 Spitzenkandidaten der Landtagswahl 1928 betrachtet. Neben einer Frau kandidierten zwei Fabrikanten, je ein Handelskammer-Syndikus, Postinspektor, Glasermeister, Forstmeister, Schultheiß, Ingenieur, Diplomkaufmann und der Generalsekretär der Partei, schließlich zwei Schulmänner $^{66}$. In ähnlicher Konstellation setzte sich auch der Landesausschuss zusammen ${ }^{67}$. Wie schon im Kaiserreich lag das Rekrutierungsfeld der Partei bei den „Gebildeten, unter den höheren und mittleren Beamten und im bürgerlichen Mittelstand“68.

59 StAnz Nr. 60 vom 14.3.1927.

60 Vgl. Frank Ra Berg (Bearb.), Biographisches Handbuch der württembergischen Landtagsabgeordneten 1815-1933, Stuttgart 2001, S. 557.

61 StAnz Nr. 236 vom 10.10.1927.

62 StAnz Nr. 255 vom 30.10.1928.

63 Art. „An die Frauen!“, Wahlnachrichten Nr. 2 vom 14.5.1928.

64 StAnz Nr. 255 vom 30.10.1928.

65 Der undatierte Aufruf wohl von 1919 im Stadtarchiv Stuttgart, Nachlass Kimmig/ Schmalzried 14/4.

66 Wahlnachrichten Nr. 2 vom 14.5.1928.

67 Vgl. etwa Schwäbischer Merkur/Kronik Nr. 101 (M) vom 1.3.1920 oder KB Nr. 106 vom 8.5.1923.

68 Karl Weller, Die Staatsumwälzung in Württemberg 1918-1920, Stuttgart 1930, S. 158.

Zeitschrift für Württembergische Landesgeschichte 74 (2015), S. 249-296.

(C) Kommission für geschichtliche Landeskunde in Baden-Württemberg und Württembergischer Geschichts- und Altertumsverein e.V.

ISSN 0044-3786 
Gemäß dem bisher Gesagten ${ }^{69}$ wird sowohl programmatisch als auch personell überaus deutlich, dass die württembergische DVP alles andere als eine Partei des großen Geldes und großindustrieller Interessen war und sich, so wie angedeutet, erheblich von manchen anderen Landesverbänden unterschied. Ihre Kandidaten und Mandatsträger reflektierten das Mitglieder- und Wählerpotenzial und damit ihr mittelständisches Profil. Sie war politische Heimat von selbständigen Kaufleuten und Gewerbetreibenden, von Angestellten, von Beamten und Freiberuflern und auch von Unternehmern ${ }^{70}$. Ihre Wählerschaft war zumeist städtisch und evangelisch. Die Landwirte Württembergs waren eine Domäne des Bauernbundes, die Katholiken wählten mehrheitlich das Zentrum, während die Arbeiter, um die man sich zwar bemühte, links votierten. Als Dilemma der Partei muss gelten, dass ihr skizziertes Wählerpotential auch von der DDP und den Deutschnationalen und später zusätzlich noch von den neuen Splitterparteien - umworben wurde und so die Chancen der Nationalliberalen begrenzt waren.

\section{Die Parteistruktur: Führung, Gremien, Ortsvereine}

Die drei zwischen 1919 und 1933 amtierenden Landesvorsitzenden der württembergischen DVP, Egelhaaf, Bickes und Rath, denen Stellvertreter zur Seite standen, kamen aus der vormaligen DP. Wie erwähnt, hatten zwei von ihnen ein kurzes Gastspiel bei der Bürgerpartei absolviert.

Der Historiker und Oberstudienrat Gottlob Egelhaaf (1848-1934), der Senior der Partei, war im Kaiserreich mehrfach erfolglos als Reichstags- und Landtagskandidat aufgetreten und hatte sich 1917 der Vaterlandspartei angeschlossen. Zu seinen zahlreichen Ehrenämtern gehörte die Mitgliedschaft im evangelischen Kirchenparlament Württembergs, zudem war er im Evangelischen Volksbund aktiv. Als Mitglied und zeitweise Vorsitzender des Württembergischen Altertumsvereins gehörte er auch dem Ausschuss des Deutschen Historikertages an. Das Amt des Landesvorsitzenden bekleidete er altersbedingt nur bis Ende Februar 1920 um

${ }^{69}$ Ein weiterer Aspekt wäre noch hinzuzufügen: Wirtschaftsminister (1930-1933) Reinhold Maier von der DDP belegt deren von der DVP unterschiedliche Rolle, indem er „als eisenfester Vertreter wirtschaftlicher Interessen" auftrat. Obwohl nicht unbedingt ein „Mann der Wirtschaft“, so wirkte er doch als deren „bester Anwalt“. Klaus-Jürgen Matz, Reinhold Maier (1889-1971). Eine politische Biographie, Düsseldorf 1989, S. 114. Zum Wirken als Minister S. 81-114. - Dass etwa der vormalige nationalliberale Ulmer Unternehmer und Parlamentarier Philipp Wieland 1918 zur DDP stieß, kann ebenfalls als Indiz für deren Nähe zur Wirtschaft gesehen werden. Vgl. zu ihm Raberg (wie Anm. 60) S. $1016 \mathrm{f}$.

70 Natürlich warb die Partei auch um diese Kreise, möglicherweise auf Spenden hoffend. Auf einem Bierabend mit nambafte(n) württembergischen Wirtschaftsvertretern in Stuttgart referierte Reichswirtschaftsminister Curtius unter Beifall über aktuelle Wirtschaftsfragen, KB Nr. 19 vom 24.1.1928. 
dann zum Ehrenvorsitzenden gewählt zu werden ${ }^{71}$. Trotz zunehmender körperlicher Gebrechen kandidierte er 1920 mit Erfolg für den Landtag, den er als Alterspräsident eröffnete. Seine langgehegten parlamentarischen Ambitionen wurden bei der Wahl von 1924 erneut befriedigt; wiederum fungierte er als Alterspräsident. Allerdings musste er nach einem Schlaganfall im Frühjahr 1926 sein Mandat niederlegen. Nach der anschließenden Erblindung erfolgte sein Rückzug aus dem öffentlichen Leben. Fraglos war sein Rückzug ein empfindlicher Verlust für seine Partei. Er war nicht nur ein überaus eifriger Parlamentarier, der etwa als Mitglied des Kirchen-Ausschusses sich insbesondere zu Kirchen- und Schulfragen äußerte. Zugleich wirkte er als produktiver Historiker, der ein umfangreiches Oeuvre hinterlie $\beta^{72}$. Egelhaaf war ein ,nationaler Mann' und sozusagen ein klassischer Nationalliberaler, der etwa am monarchischen Gedanken festhielt, jedoch stets als konzilianter Politiker auftrat.

Auf seinen Vorschlag wurde Theodor Bickes (1868-1933) 1920 zum neuen Landesvorsitzenden gewählt ${ }^{73}$. Der in Pirmasens Geborene hatte Naturwissenschaften und Nationalökonomie studiert und arbeitete als Chemiker auch in den USA. Vor der Jahrhundertwende kam er nach (Stuttgart-) Feuerbach und wirkte als Gemeinderat. Sein Engagement für das Rote Kreuz führte ihn im Weltkrieg als Leiter von Lazarettzügen zu verschiedenen Kriegsschauplätzen. Dafür zum Hofrat ernannt, blieb er auch nach dem Krieg für das Rote Kreuz aktiv. Für die DP kandidierte er 1906 erfolglos zum Landtag; seit 1912 war er deren stellvertretender Landesvorsitzender. 1913 begründete er die „Schwabenwarte“, ein nationalliberales Wochenblatt, auf das noch zurückzukommen ist. Bickes wurde 1920 und 1924 in den Landtag, 1924 auch in den Reichstag gewählt. Da die Partei keine Doppelmandate wünschte ${ }^{74}$, legte er sein Landtagsmandat zu Gunsten des Postsekretärs Hartmann nieder. Im Herbst 1927 gab er den Parteivorsitz ab und begründete dies mit seiner Inanspruchnahme in Berlin. Auf seinen Vorschlag trat Schultheiß Rath die Nachfolge $\mathrm{an}^{75}$. Bickes wurde 1928 erneut in den Reichstag gewählt, dem er bis 1930 angehörte. Egelhaaf, der ihn schätzte, beschrieb „sein robustes, derbes Äußeres“ und seine Rednergabe und betonte, seine „Beziehungen zur Industrie“ hätten „nicht unerheblich“ bei der Beschaffung von Geldmitteln für die Partei geholfen ${ }^{76}$.

${ }^{71}$ Schwäbischer Merkur/Kronik Nr. 101 vom 1.3.1920 (M).

72 Vgl. zum Obigen seine Lebenserinnerungen und RABERG (wie Anm. 60) S. $138 \mathrm{ff}$. mit Verzeichnis seiner Veröffentlichungen.

73 Schwäbischer Merkur/Kronik Nr. 101 vom 1.3.1920 (M).

74 Egelhaaf (wie Anm. 7) S. 167.

${ }^{75}$ StAnz Nr. 236 vom 10.10.1927. Rath war 1924 bereits zu einem der Stellvertreter des Landesvorsitzenden gewählt worden, KB Nr. 155 vom 4.7.1924.

76 Egelhaaf (wie Anm. 7) S.150. - Vgl. auch Raberg (wie Anm.60) S. 70 f. Dort wird auch Bickes’ Artikel über das Rote Kreuz angeführt. 
Der langjährige Schultheiß von Lustnau bei Tübingen, Johannes Rath (18761945 ${ }^{77}$ stand bis zum Ende des Landesverbandes 1933 an dessen Spitze. Auch er kam aus der DP und ging wohl 1919 zur DVP, die er von 1924 bis 1932 im Landtag vertrat, wo er häufig sprach. Der umtriebige Mann war landesweit bekannt, äuBerte er sich doch häufig in Zeitungsartikeln, die auch Aufnahme in der Provinzpresse fanden, zu aktuellen landespolitischen Fragen. Über lange Jahre war er zudem Vorsitzender der Vereinigung württembergischer Ortsvorsteher, auf deren Landestagungen er sich - wie im Landtag - kompetent zu Fragen der Kommunalpolitik äußerte und standespolitische Forderungen vertrat ${ }^{78}$. Auf seine und seiner Vorgänger politische Arbeit wird noch eingegangen.

Die drei Parteiführer, auch in den Reichsgremien vertreten, agierten als Wahlkämpfer und referierten während der Ausschusssitzungen und Landesversammlungen - Egelhaaf und Rath zumeist zur Innen-, Bickes zur Reichspolitik. Sie waren geradezu enthusiastische Vertreter der Politik Stresemanns und zeichneten sich durch maßvolles, konziliantes und staatstragendes Verhalten aus; über charismatische Führereigenschaften verfügten sie nicht.

Während der Anfänge der Partei lag die Organisationsarbeit im Argen, ablesbar etwa am häufigen Wechsel der Parteisekretäre. Erst mit dem Amtsantritt des Generalsekretärs Dr. Maerz 1924 verbesserten sich die Verhältnisse nachhaltig. Er fungierte auch als Schriftleiter der „Schwabenwarte“, die 1925 zum Parteiorgan erklärt wurde $^{79}$. Ihr ist zu entnehmen, dass Maerz häufig in den Ortsvereinen als Redner auftrat. Er verließ sein Amt $1929^{80}$.

Oberste Parteiinstanz war die Vertreterversammlung, die häufig in Verbindung mit der Landesversammlung stattfand. Zu den Kompetenzen der Vertreter gehörten u.a. die Nominierung der Kandidaten, die Entgegennahme des Geschäftsberichtes und die Wahl des Landesausschusses aus ihrer Mitte. In der Regel tagte das Gremium mindestens einmal jährlich und verabschiedete auch Resolutionen. Ihm gehörten u. a. die Parlamentarier der Partei und die Mitglieder des Landesausschusses, regionale und örtliche Vertreter und solche der Arbeitsgemeinschaften an.

In dem im vierjährigen Turnus formierten Landesausschuss saßen u. a. wiederum die Parlamentarier, die württembergischen Mitglieder des Berliner Zentralvorstands, der Generalsekretär sowie mindestens 40 aus der Vertreterversammlung Gewählte. Aus der Mitte des Landesausschusses formierte sich als verkleinertes Organ der Geschäftsführende Ausschuss. Zudem wurden auch hier

77 Er feierte 1927 sein 25-jähriges Amtsjubiläum und wurde zum Ehrenbürger ernannt, KB Nr. 61 vom 15.3.1927.

78 Vgl. z.B. KB Nr. 177 vom 2.8.1926. - Kurzinformationen zu Rath bei RAberg (wie Anm. 60) S. 692.

79 Angeblich handelte es sich dabei um eine neue Gründung (KB Nr.51 vom 3.3.1925), obwohl die Wochenschrift, wie erwähnt, schon seit 1913 existierte. In der Stuttgarter Landesbibliothek sind nur der Jahresband 1913, einige wenige Exemplare von 1928 sowie der Jahrgang 1929 vorhanden.

80 Schwabenwarte Nr. 25, 1929. 
für die Partei wichtige Entscheidungen getroffen. Sitzungen fanden nach Bedarf statt $^{81}$.

Die nicht alljährlichen Landesversammlungen, auf denen Stresemann mehrfach als Redner auftrat ${ }^{82}$, zielten vor allem auf die breite Öffentlichkeit. Als Zeichen der Parteikrise gilt die Tatsache, dass die letzte Versammlung 1931 stattfand.

Während die DVP schon frühzeitig über Ortsvereine in den größeren Städten Württembergs verfügte, ist davon auszugehen, dass spätestens seit Mitte der 1920er Jahre solche auch in den übrigen Oberamtsstädten und Zentralorten - jedenfalls in den überwiegend evangelischen Gebieten - existierten ${ }^{83} .1925$ schlossen sich die Ortsvereine aus den Oberämtern Crailsheim, Gaildorf, Gerabronn, Hall, Künzelsau und Mergentheim zu einem Kreisverband zusammen ${ }^{84}$. Während der Crailsheimer Gründung wurde übereinstimmend von einer günstigen Aufwärtsentwicklung berichtet.

Diese Entwicklung wurde in den 1920er Jahren häufig betont. So begrüßte Egelhaaf im Februar 1920 das allenthalben einsetzende rasche Wachstum seiner Partei, Sachs betonte, der Zugkraft Egelhaafs habe man es zu verdanken, dass die Zahl der Mitglieder im Lande aufs Fünffache gestiegen sei ${ }^{85}$. Im Januar 1922 sprach der Generalsekretär während der Vertreterversammlung wiederum von einer Aufwärtsbewegung ${ }^{86}$, während ein Jahr später dort dieser Trend bestätigt wurde. Die Zahl der Mitglieder habe schon längst die der früheren DP überschritten ${ }^{87}$. Während insgesamt keine konkreten Mitgliederzahlen zu ermitteln waren, konstatierte Bickes 1927 vor der Vertreterversammlung, die Partei sei inzwischen zu einem kräftigen Stamme herangewachsen ${ }^{88}$.

Neben den bereits erwähnten berufsspezifischen Ausschüssen (und dem Frauenausschuss) ist noch auf eine regional formierte Arbeitsgemeinschaft der südwestdeutschen Nationalliberalen aus Baden, Hessen-Darmstadt, Nassau, der Pfalz und Württemberg hinzuweisen. Für Bickes hatte sich dieses seit Anfang der 1920er Jahre existierende Forum „auf das Beste bewährt“, habe man doch so „Einfluß auf die

${ }^{81}$ Satzung der Deutschen Volkspartei (Nationalliberale Partei) in Württemberg, Stuttgart 1920.

82 So war die Landesversammlung 1923 von Tausenden besucht; die Rede Stresemanns galt dem Merkur als Stunde nationaler Erbebung, KB Nr. 18 vom 23.1.1923.

83 Vgl. dazu die Schwabenwarte 1928 und 1929.

${ }^{84}$ KB Nr. 252 vom 28.10.1925. Da die Gründung auf einen Beschluss des Landesausschusses erfolgte, gab es ähnliche Initiativen wohl auch anderswo.

${ }^{85}$ Schwäbischer Merkur/Kronik Nr. 101 vom 1.3.1920 (M). Konstituierende Sitzung des Landesausschusses.

${ }^{86} \mathrm{~KB}$ Nr. 12 vom 16.1.1922.

${ }^{87} \mathrm{~KB}$ Nr. 18 vom 23.1.1923. Zu Kriegsbeginn dürfte die Mitgliederzahl der DP etwa 10.800 betragen haben. Vgl. Andreas Gawatz, Wahlkämpfe in Württemberg. Landtags- und Reichstagswahlen beim Übergang zum politischen Massenmarkt (1889-1912), Düsseldorf 2001, S. 88.

${ }^{88}$ StAnz Nr. 94 vom 25.4.1927. 
Partei erlangt“ und sei stets informiert gewesen ${ }^{89}$. Im Gegensatz etwa zu den rheinisch-westfälischen Verbänden, die „den rechten, schwerindustriellen Flügel“ repräsentierten, waren die Südwestdeutschen Befürworter der Politik Stresemanns ${ }^{90}$. Offenbar gab bei ihnen der ehrgeizige hessische Landesvorsitzende Dingeldey weitgehend den Ton an.

\section{Die DVP und die württembergische Innenpolitik bis zur Landtagswahl von 1928}

Bei den Landtagswahlen vom Juni 1920 konnte die DVP mit ihrer unfertigen Organisation nur vier Abgeordnete in das 101-köpfige Parlament entsenden: Bickes, Egelhaaf, den kriegsversehrten Postsekretär Christian Hartmann ${ }^{91}$ und den Ulmer Handelsschulrat und Vorsitzenden der dortigen Ortsgruppe, Jakob Roßmann ${ }^{92}$. Das „kleine Häuflein“93, das keinen Fraktionsstatus hatte, sondern als „Gruppe“ galt, war sich seiner bescheidenen Rolle durchaus bewusst. Die Wirkungsbereiche im Landtag hatte man aufgeteilt. Egelhaaf war insbesondere für Kirchen- und Schulfragen zuständig; das Zentrum hatte ihm als Sachkundigen einen Ausschusssitz abgetreten ${ }^{94}$. Bickes als Vorstand der Gruppe gehörte zur „ersten Garnitur“ der Redner, Hartmann widmete sich Beamten-, Arbeits- und Ernährungsfragen, Roßmann war schließlich für volkswirtschaftliche Themen eingeteilt ${ }^{95}$. Die Gruppe war gewillt, in völliger organisatorischer Unabhängigkeit nach links und nach rechts zu agieren ${ }^{96}$, d. h. die Regierung zu tolerieren, ihr jedoch nicht anzugehören. So sah man sich als „Zünglein an der Waage“97 und war zur konstruktiven Mitarbeit bereit. In seiner Jungfernrede am 22. Juni 1920 appellierte Egelhaaf an die Fraktionen, Ausgleich und Kompromiss zu suchen und sich gegenseitig zu vertrauen ${ }^{98}$.

Anfang November 1920 argumentierte er in der Haushaltsdebatte ähnlich, und seine Tochter meinte, er habe dabei den Sozialdemokraten zugeredet wie ein Vater irrenden Kindern ${ }^{99}$. Die Rolle seiner Partei im Landtag charakterisierte er 1921 als

89 Zitiert nach Richter, Die Deutsche Volkspartei (wie Anm. 1) S. 161.

90 Ebd. - Vgl. dazu etwa die Entschließung der südwestdeutschen Arbeitsgemeinschaft von Mitte September 1929, in der dem Parteiführer Dank und Anerkennung ausgesprochen wurde, KB Nr. 219 vom 18.9.1929.

${ }_{91} \mathrm{Zu}$ ihm Raberg (wie Anm. 60) S. 321.

92 Ebd., S. 738.

93 Egelhaaf (wie Anm. 7) S. 157.

94 Ebd., S. 151.

95 Ebd., S. 150 f.

${ }_{96}$ Konstituierende Sitzung des Landesausschusses, HT Nr. 51 vom 2.3.1920.

97 Egelhata (wie Anm. 7) S. 149.

98 Landtag vom 22.6.1920, S. $1 \mathrm{f}$.

99 Egelhata (wie Anm. 7) S. 156. 
sachliche Politik; ihr Eintreten für Hieber habe dessen Regierung erst möglich gemacht, auch wenn dieser Entschluss nicht leicht gefallen sei ${ }^{100}$ - schließlich hatte Hieber die Liquidierung der DP betrieben. Im April 1921 zollte Bickes der Regierung Lob, habe sie doch die Staatsautorität wiederbergestellt. Er sah die Schuld am Weltkrieg bei Deutschlands Gegnern, lehnte eine Zusammenarbeit mit der USPD und den Kommunisten ab und plädierte für Einbeziehung der Sozialdemokratie. Allerdings lehne seine Partei den Klassenkampf und den Internationalismus ab. Zugleich sah er es als deren fortdauernde Aufgabe, die Gegensätze zwischen rechts und links auszugleichen; zwischen den bürgerlichen Parteien stellte er eine Annäberung fest ${ }^{101}$. Ende 1922 äußerte er sich zum Nationalsozialismus. Er sei wohl keine Arbeiterpartei, sondern Sammelbecken vieler mit Kriegsausgang und Revolution unzufriedenen Elementen aus allen Volksschichten ${ }^{102}$.

Nach dem Scheitern der Regierung Hieber - Grund war letztlich die zum Dauerthema werdende Frage der Auflösung der kleinen Oberämter -, wurden auf den 4. Mai 1924 Landtags- und Reichstagswahlen ausgeschrieben. Die DVP operierte mit der Parole Durch Arbeit und Opfer zur Freibeit ${ }^{103}$, allein der betagte Egelhaaf bestritt 18 Versammlungen ${ }^{104}$.

Dennoch konnte ein durchschlagender Erfolg nicht erzielt werden, entfielen doch im auf 80 Abgeordnete reduzierten Landtag nur drei Mandate auf die Partei ${ }^{105}$. Der Sitz des auch in den Reichstag gewählten Bickes ging an Hartmann, Rath kam als parlamentarischer Neuling, Egelhaaf trat sein Mandat dann 1926 an Frau Heyd $a b^{106}$.

Die nunmehr etablierte Rechtskoalition unter Staatspräsident und Kultminister Bazille, in der die Zentrumspolitiker Bolz und Beyerle ihre bisherigen Ministerämter behielten, war letztlich alternativlos. Die DVP war nicht gewillt, einer Koalition aus Zentrum, Demokraten und SPD beizutreten, war sie doch der Ansicht, dass die DNVP auch aus Gründen der Reichspolitik zur Verantwortung mit herangezogen werden müsse ${ }^{107}$. Dabei dürfte auch der Wandlungsprozess Bazilles mit ausschlaggebend gewesen $\operatorname{sein}^{108}$. So entschlossen sich die Nationalliberalen,

100 Vertretertag im März 1921, KB Nr. 61 vom 15.3.1921.

101 Landtag vom 15.4.1921, S. 1893-1899.

102 Landtag vom 19.12.1922, S. 4087-4089.

103 Anzeige im KB Nr. 94 vom 22.4.1924.

104 Egelhata (wie Anm. 7) S. 163. Auf einzelne Versammlungen wurde bereits eingegangen.

105 Sie war allerdings durch „die Ungerechtigkeit des Wahlrechts“ benachteiligt. So erhielt 1924 die DDP, die etwa die doppelte Stimmenzahl errang, neun Mandate. Raberg (wie Anm. 60) S. XLII. Zum Landtagswahlrecht insgesamt ebd., S. XXXIX-XLIII.

$106 \mathrm{~KB}$ Nr. 275 vom 24.11.1926.

107 Egelhaaf (wie Anm. 7) S. 163.

108 Vgl. dazu Hans Peter Müller, Wilhelm Bazille. Deutschnationaler Politiker, württembergischer Staatspräsident 1874-1934, in: Lebensbilder aus Baden-Württemberg, Bd.21, 2005, S. 480-517, hier S. $493 \mathrm{ff}$. 
wenn auch mit Vorbehalten, zur Unterstützung des Kabinetts ${ }^{109} .1926$ konstatierte Rath, dass mit einer Regierung unter Ausscheidung der Rechten nicht viel zu gewinnen ist. Zudem war er sich bewusst, als kleine Partei sei man ohnehin nicht im Stande, den Gang der Politik entscheidend zu beeinflussen. Dennoch wirke man häufig als Zünglein an der Waage und sei so für die Regierung besonders wert$v_{o l l}{ }^{110}$. Im Herbst bescheinigte er der Regierung, vielfach eine Politik der mittleren Linie, die keinen auffallend rechtsradikalen Charakter trage und so weitgehendste Unterstützung rechtfertige. Kritik äußerte Rath an der Schullastenverteilung zwischen Staat und Gemeinden, die ihm als Schultheiß die kommunale Finanzlage zu wenig berücksichtige, sowie an der Berufung von Parlamentariern in höbere Beamtenstellen ${ }^{111}$.

Im Frühjahr 1927 betonte Hartmann während der Vertreterversammlung, man stehe der Regierung mit woblwollender Neutralität gegenüber, die allerdings nicht beim Schullastenausgleich und beim Gewerbesteuergesetz gegolten habe. Zudem konstatierte er die Abhängigkeit vom Bauernbund, die insbesondere auf dem Gebiet des Schulwesens zum Ausdruck komme ${ }^{112}$.

Bei der Betrachtung weiterer landespolitischer Aktivitäten der DVP bis zum Wahljahr 1928 wird deutlich, dass insbesondere Johannes Rath rasch an Profil gewann. Während er einerseits kommunale Interessen artikulierte, trat dabei andererseits wiederum das soziale bzw. mittelstandsorientierte Wollen der Partei zu Tage. Ende Oktober 1924 präsentierte er im Landtag einen Katalog von Forderungen, zu denen u. a. die baldige Vorlage einer neuen Bezirks- und Gemeindeordnung und die bessere Unterstützung der Gemeinden gehörten. Außerdem plädierte er für die Erhöhung des Wahlalters, ein Pflichtarbeits-Dienstjahr für die Jugend sowie deren Aufklärung über die Gefahren des Alkohols ${ }^{113}$.

Besonders am Herzen lag ihm der Kampf um die Gebäudeentschuldungsteuer, deren Verdoppelung er befürchtete. Dazu hatte er im Landtag eine Kleine Anfrage eingebracht, die darauf zielte, die Regierung zu bewegen, kein Mittel unversucht zu lassen, um bei der Reichsregierung einen Abbau zu erreichen ${ }^{114}$. Etwas später konstatierte er resigniert, über dieser Frage stehe kein guter Stern ${ }^{115}$.

Bei der Generaldebatte zum Haushalt Ende März 1926 sprach sich Rath gegen einen zweijährigen Etat aus und begrüßte die Vorlage eines Ministerpensionsgesetzes. Dabei bescheinigte er der Regierung, keineswegs beamtenfeindlich zu sein. Bemerkenswert war seine Missbilligung der Verhaftung zweier kommunistischer

109 Egelhaaf (wie Anm. 7) S. 163.

110 Rede auf dem Landesparteitag, KB Nr. 90 vom 20.4.1926.

111 Rede auf der Herbsttagung in Heilbronn, KB Nr. 257 vom 3.11.1926. Vgl. zur Kritik an der Verbeamtung von Parlamentariern auch die Stellungnahme des geschäftsführenden Landesausschusses, KB Nr. 163 vom 16.7.1926.

112 StAnz Nr. 94 vom 25.4.1927.

113 Landtag vom 24.10.1924, S. 325-330.

114 Aufsatz, im KB Nr. 48 vom 27.2.1926.

115 Landtag vom 26.3.1926, S. 2255-2261. 
Abgeordneter. Nachdem einem von ihnen ein Disziplinarverfahren mit dem Ziel seiner Entlassung aus dem Bahndienst drohte, äußerte er sein Bedauern ${ }^{116}$ und bekundete damit seine liberale Grundhaltung auch gegenüber politischen Gegnern.

Lob artikulierte er in einem Aufsatz zum Wohnungsbauprogramm der Regierung, die außergewöhnlich hohe Mittel zu dessen Förderung bereitgestellt habe. Die Bebebung der Wohnungsnot war ihm ein zentrales Thema. Damit verband er die Hoffung auf Aufhebung der Zwangsbewirtschaftung, mit der allerdings ein Mieterschutz einhergehen müsse. Bedauerlich erschien ihm jedoch, dass auf stenerlichem Gebiet nicht mehr geschehe, um auch so den Wohnungsbau anzukurbeln ${ }^{117}$.

Während Rath im Januar 1927 in einem weiteren Aufsatz kompetent die Neuregelung der württ. Gewerbestener erläuterte ${ }^{118}$, äußerte er sich im März eher kritisch zu einem Gesetzentwurf über die Dienstverhältnisse der Minister. Gleichzeitig betonte er die zwingende Notwendigkeit zur Sparsamkeit im Land wie im Reich $^{119}$. Bei der Beratung des Polizei-Verwaltungsgesetzes plädierte er angesichts des Verhaltens der Radikalen für die Aufrechterhaltung von Ruhe und Ordnung. Die Regierung benötige ein zuverlässiges Instrument, eine gemeindliche Polizei sei dazu nicht geeignet ${ }^{120}$. In einer Rede gegen die Auswüchse des Hausierhandels äußerte er zwar Verständnis für den in einigen Gemeinden bodenständig betriebenen Handel, generell sei das Hausieren jedoch mit allen Mitteln einzudämmen. Dies diene dem Schutz der ortsansässigen Geschäfte, aber auch die Landbevölkerung sei vor aufdringlichen Hausierern zu schützen. Zudem geißelte er, dass neuerdings selbst Großbetriebe auf diesem Gebiet mit Autos aktiv würden ${ }^{121}$.

Eminent politisch waren die Ausführungen des neuen Parteivorsitzenden bei der Beratung des Haushalts für 1928. Er bekannte sich schnörkellos zum deutschen Einheitsstaat, den er für eine eher ferne Zukunft kommen sah. Dementsprechend wollte er, gegen die württembergische Regierung gewandt, kein engeres Zusammenwirken mit Bayern und auch keine preußische Provinz werden. Die Haltung seiner Partei zur Regierung bleibe ansonsten unverändert, auch wenn man die Rolle des Bauernbundes kritisch sehe und so weiterhin sachliche Kritik übe ${ }^{122}$. Mehrfach äußerte sich Rath auch systemkritisch, etwa wenn er forderte, man solle langsamer treten in der Gesetzesfabrikation ${ }^{123}$ oder den bemmungslosen Parlamentarismus geißelte. Stattdessen gelte es, mehr und billiger zu arbeiten und

116 Ebd.

117 Aufsatz: „Zum Wohnungsbauprogramm der Württ. Regierung“, KB Nr.96 vom 27.4.1926.

118 KB Nr. 6 vom 10.1.1927.

119 Landtag vom 17.3.1927, S.3628f.

120 Landtag vom 31.5.1927, S. 3835-3838.

121 Landtag vom 10.6.1927, hier zitiert nach dem Abdruck im KB Nr.146 vom 27.6.1927. Das Blatt fand seine Aussagen beachtenswert.

122 Landtag vom 4.11.1927, S. 4306-4311. Im Landtag vom 28.1.1928 (S. 4749f.) sprach sich Rath erneut - mit starker Kritik an Bazilles konträrer Position - für den Einheitsstaat aus.

${ }^{123}$ Landtag vom 4.11.27, S. 4306-4311. 
zu sparen. Schließlich forderte er eine weitgebende Aufklärungstätigkeit im Vol$k e^{124}$.

Sein Kollege Hartmann widmete sich konkreten landespolitischen Themen. Nachdem er der Regierung bescheinigt hatte, dass in der Kulturverwaltung Württembergs nicht jene Irrungen anderer Länder eingetreten seien ${ }^{125}$, sprach er sich 1928 für die lückenlose Einführung des achten Schuljahres aus, befürchtete er hier doch Sabotageversuche von rechter Seite ${ }^{126}$. Warm setzte er sich auch für die Belange der Kriegsopfer ein ${ }^{127}$ und nahm Anteil an den Problemen der Landwirtschaft ${ }^{128}$.

\section{Von den Landtagswahlen 1928 bis zum Eintritt in die Regierung}

Im Dezember 1927 beschäftigte sich der Landesausschuss mit den kommenden Landtags- und Reichstagswahlen. Man war sich einig, mit aller Entschiedenheit zu kämpfen, allerdings weniger gegen die anderen bürgerlichen Parteien, als gegen die Wablmüdigkeit und die unseligen Splittergruppen wie Volksrecht- und Wirtschaftspartei ${ }^{129}$.

Die inzwischen organisatorisch gefestigte Partei trat neben ihren Versammlungen mit großformatigen und mehrseitigen „Wahlnachrichten“ an die Öffentlichkeit. Deren zweite Ausgabe ${ }^{130}$ stellte die schon genannten Spitzenkandidaten vor und präsentierte den Wahlaufruf, der einleitend betonte, man wolle auf kleinliches Parteigezänk verzichten. Die bisherige Haltung im Landtag habe sich an den Taten der Regierung orientiert und dabei nicht selten Veranlassung zu energischer Opposition geliefert. Hauptaufgabe sei jedoch nicht Kritik sondern positive Mitarbeit gewesen. Die wichtigsten Programmpunkte ließen wie schon erwähnt deutlich soziale und mittelstandsorientierte Schwerpunkte erkennen. Schließlich wurde die Durchfübrung des 8. Schuljahrs angemahnt.

Mehrfach wurde gegen das Grundübel der neuen Splitterparteien und deren einseitige Interessenpolitik (Lisbeth Heyd) zu Felde gezogen, musste man doch hier Stimmenverluste befürchten. Jedweden Radikalismus gelte es als Todfeind des Bürgertums zu bekämpfen (Parteisekretär Maerz). In einem längeren Artikel zog Johannes Rath eine letztlich negative Bilanz der Regierung Bazille. Sie habe kein einziges Gesetzgebungswerk von größerer Bedeutung vorgelegt und auch keine nennenenswerte $(n)$ Reformen bewirkt und so die geweckten starken Erwartungen

\footnotetext{
124 Landtag vom 12.1.1928, S. 4445-4449.

125 Landtag vom 5.6.1926, S. 2643-2646.

126 Landtag vom 7.2. 1928, S. $4919 \mathrm{f}$.

127 Landtag vom 10.6.1927, S. 3987f. Landtag vom 24.1.1928, S. 4634-4638.

128 Landtag vom 10.6.1927, S. 3987f. Landtag vom 18.1.1928, S 4544-4546.

129 StAnz Nr. 290 vom 12.12.1927.

130 „Was jeder Wähler wissen muß“, Wahlnachrichten Nr.2 vom 14.5.1928. Daraus das Folgende (Zitate im Original z.T. in Fettdruck).
} 
nicht erfüllt. Die unter sich uneinige Koalition habe zudem die dringende Neueinteilung der Bezirke verschleppt, die wirkliche Einführung des achten Schuljahres versäumt, die Schullastenverteilung von 1925 sei rückschrittlich. Einzig beim Wohnungsbau und bezüglich der Universität Tübingen sah Rath Erfolge.

Diese Einschätzung wurde in weiten Kreisen geteilt, kommentierte doch das Stuttgarter "Neue Tagblatt" den Wahlausgang vom 20. Mai mit den Worten, die Politik Bazille ist gerichtet, hatten doch die Deutschnationalen die Hälfte ihrer bisherigen Sitze verloren. Zugleich bezeichnete das Blatt die Zersplitterung im Bürgertum als verheerend ${ }^{131}$. Während sich die SPD als Wahlsieger fühlen und das Zentrum seine Stellung behaupten konnte, mussten Bauernbund und DDP je einen Sitz abgeben, der Christliche Volksdienst hatte auf Anhieb drei Mandate errungen, die DVP einen zusätzlichen vierten Sitz gewonnen. Für sie kehrten Hartmann und Rath in das Landesparlament zurück, Handelskammer-Syndikus Dr. Paul Burger ${ }^{132}$ und Glaserobermeister Karl Mayer ${ }^{133}$ traten als parlamentarische Neulinge hinzu.

Zur insgesamt dramatisch verlaufenden Regierungsbildung ${ }^{134}$ erklärte der erweiterte geschäftsführende Landesausschuss der DVP Anfang Juni, man wolle sich einem Ruf zur Beteiligung nicht verschließen. Voraussetzung sei allerdings ein Kurs, der mehr als bisher von der Mitte bestimmt werde. Zwar wünsche man ein verbessertes Verhältnis zur Opposition, erstrebe allerdings eine Koalition aller bürgerlichen Kreise ${ }^{135}$. Eine solche kam jedoch nur als Minderheitsregierung unter dem neuen Staatspräsidenten Bolz vom Zentrum zu Stande. Nachdem die vor allem von ihm in die Opposition gedrängten Sozialdemokraten Misstrauensvoten gegen die Gesamtregierung und den als Kultminister nominierten Bazille initiiert hatten, votierten auch die Nationalliberalen prinzipientreu gegen diesen. Der „Merkur“ kommentierte, die Partei sei gegen allen Druck von rechts fest geblieben und durch ihre Haltung gegen Bazille von einer Regierungsbeteiligung abgeschnitten. Dennoch sagte das Blatt zutreffend voraus, sie werde sich zur Regierung rein sachlich verhalten. Die deutschnational orientierte "Süddeutsche Zeitung“ wusste von widerstrebenden Meinungen innerhalb der DVP zu berichten ${ }^{136}$.

Im September 1928 stellte Rath fest, seine Partei nehme sogar eine Regierungskrise in kauf, sofern nicht in Kultfragen und hier insbesondere bei der konsequenten Einführung des achten Schuljahres ein ihr genehmer Kurs gesteuert wer$\mathrm{de}^{137}$. Ende Oktober nannte er die jetzigen Verhältnisse in der Landespolitik wenig

131 Zit. Nach StAnz Nr. 118 vom 22.5.1928. Dort auch die Wahlergebnisse.

132 Zu ihm Raberg (wie Anm. 60) S. 111.

${ }^{133} \mathrm{Zu}$ ihm ebd., S. 557.

134 Vgl. dazu etwa Besson (wie Anm. 3) S. 35-40; Schnabel, Württemberg (wie Anm. 3) S. $48 \mathrm{f}$.

135 KB Nr. 129 vom 5.6.1928.

136 Pressestimmen im KB Nr. 134 vom 11.6.1928.

137 Versammlung in Tübingen, StAnz Nr. 218 vom 17.9.1928. 
befriedigend und dentete sogar die Möglichkeit einer großen Koalition in Württemberg $a n^{138}$. Dies war allerdings eine theoretische Option, wurde doch während einer Stuttgarter Mitgliederversammlung im Februar 1929 als beste Problemlösung der gemeinsame Eintritt von DDP und DVP in die Regierung befürwortet; er ermögliche auch der SPD eine sachliche Mitarbeit ${ }^{139}$.

Ende März 1929 geriet die Regierung in eine noch kritischere Lage. Nach einem Urteil des Leipziger Staatsgerichtshofs waren der Volksrechtspartei und der NSDAP, die gegen das württembergische Wahlgesetz geklagt hatten, drei Landtagsmandate zu Lasten von Bauernbund, SPD und Zentrum zuzuteilen. Nunmehr, so Generalsekretär Maerz, könne eine Mebrbeitsbildung allein durch die DVP nicht mehr erzielt werden. Er bezeichnete daher den Regierungseintritt seiner Partei und der DDP als staatspolitische Notwendigkeit. Die DVP dränge sich nicht anf, werde sich jedoch, sofern ibr Einfluß gewabrt sei, auch nicht versagen ${ }^{140}$. Später bekräftigte der Vorsitzende Rath das Ziel eines gemeinsamen Eintritts mit den Demokraten, das zu einer Stärkung auch der eigenen Position, einer Politik der mittleren Linie und einer aktionsfähigen Regierung führe ${ }^{141}$.

Während in der DDP unterschiedliche Meinungen herrschten und sich das Zentrum letztlich abwartend verhielt ${ }^{142}$, verfolgte vor allem Rath weiterhin den Regierungseintritt. Er kritisierte im Landtag ${ }^{143}$ das Regieren mit wechselnden Mebrbeiten als unhaltbar und konnte sich verschiedene Lösungsmöglichkeiten vorstellen. Allerdings suchte er Mitsprache für die beiden liberalen Parteien ${ }^{144}$. Dabei erhoffte er auch Impulse für Reformvorhaben wie die dringliche Flurbereinigung bei der Bezirkseinteilung ${ }^{145}$.

Rückte die DVP durch ihre Zustimmung zu einem Misstrauensantrag der DDP gegen Kultminister Bazille ${ }^{146}$ näher an die Demokraten, ebnete eine gemeinsame Kundgebung von Zentrum, DDP und DVP gegen das von der Rechten unterstützte Volksbegehren gegen den Youngplan ${ }^{147}$ den Weg zur Kooperation. Nachdem das

138 Versammlung in Reutlingen, KB Nr. 252 vom 26.10.1928.

139 StAnz Nr. 40 vom 16.2.1929.

140 StAnz Nr. 75 vom 30.3.1929 (Beitrag in der Schwabenwarte).

141 Rede während des Landesparteitages, KB Nr. 81 vom 8.4.1929.

${ }^{142}$ Vgl. dazu etwa den Artikel „Zur politischen Lage in Württemberg“, KB Nr. 87 vom 15.4.1929.

143 Dort hatte er sich am 16. Februar 1929 (S. 408 ff.) und 13.März (S. 748 f.) Lob und Tadel verteilend, kompetent zur neuen Gemeindeordnung geäußert. Vgl auch StAnz Nr. 53 vom 4.3.1929.

${ }^{144}$ Seine Rede vom 18.4.1929 beinhaltete zudem eine Fülle von z. T. etwas nebulösen Ausführungen über den möglich Bankrott des Parlamentarismus oder eine Diktatur, zu neuen Strömungen oder zum Denken der Jugend, Landtag vom 18.4.1929, S. 825-830.

${ }^{145}$ Vgl. dazu die Parteiversammlung in Heilbronn, KB Nr.113 vom 16.5.1929.

$146 \mathrm{~KB} \mathrm{Nr} .99$ vom 29.4.1929.

147 StAnz Nr. 246 vom 19.10.1929. Der Youngplan, der den Dawesplan ablöste, regelte die deutschen Reparationszahlungen. Vgl. dazu als landespolitisches Problem Besson (wie Anm.3) S.65-75. - Die Abneigung der DVP gegen die das Volksbegehren mittragende 
Volksbegehren für die Rechtsparteien mit einem Misserfolg endete, hatte sich der geschäftsführende Ausschuss der DVP am 20. November für einen Eintritt in die Regierung ausgesprochen. Ein wichtiges Motiv war dabei auch, das „Lebenswerk “ Stresemanns durch eine Zustimmung der württembergischen Regierung zum Youngplan im Reichsrat zu sichern ${ }^{148}$. Anschließend kursierten Gerüchte über Verhandlungen zwischen Bolz und Rath, dem angeblich das Wirtschaftsministerium angeboten worden sei. Rath wies diese Meldungen jedoch als frei erfunden zurück $^{149}$. Am 11. Januar 1930 sprach sich der Landesausschuss der DVP für eine Wiederaufnabme der seit Frühjahr 1929 mit der DDP geführten informellen Gespräche zur Regierungsbeteiligung aus; man erstrebe dazu eine Art gemeinsamer Front. Rath sah in den meisten Planungen der Regierung geeignete Verhandlungsgrundlagen und konstatierte, bei den Demokraten sei man grundsätzlich zum gemeinsamen Regierungseintritt bereit ${ }^{150}$.

Mitte Januar 1930 ging der Prozess dann rasch über die politische Bühne. In der DDP war es vor allem deren Vorsitzender Bruckmann, der den beträchtlichen Widerstand innerhalb seiner Partei gegen den Regierungseintritt überwinden konnte. Die Berufung zweier Minister, von der DDP und DVP ursprünglich ausgingen, erwies sich bei den Gesprächen mit Bolz als nicht durchsetzbar. Am 19. Januar wurde die Ernennung von Reinhold Maier zum Wirtschaftsminister und Johannes Rath zum ehrenamtlichen Staatsrat bekannt gegeben. Letzterer begrüßte im „Merkur" das Zusammenrücken der beiden Parteien als den vitalsten Interessen des liberalen Bürgertums entsprechend und betonte, $\mathrm{da}$ in Berlin alles wankt und fällt und vielfache Bedrängnis herrsche, müssten im Süden gewisse Ordnungszellen vorbanden sein ${ }^{151}$. Wäbrend einer gemeinsamen Versammlung der beiden liberalen Parteien in Gmünd begrüßte Rath im Februar, daß der liberale Gedanke wieder marschiere und bezeichnete die beidseitigen Bestrebungen hoffnungsvoll als etwas Großes ${ }^{152}$. Im Mai erklärte er vor der Vertreterversammlung seiner Partei, die neue Koalition arbeite gut und reibungslos ${ }^{153}$.

DNVP wurde bereits im Februar 1929 artikuliert. Man polemisierte gegen den neuen Parteidiktator Hugenberg und dessen reaktionären sozialpolitischen Kurs und konstatierte innere Kämpfe in der Partei und mit dem Zentrum. Sitzung des Arbeiter- und Angestellten-Ausschusses der DVP, StAnz Nr. 36 vom 12.2.1929.

${ }^{148}$ Vgl. Besson (wie Anm.3) S. 75.

149 KB Nr. 300 vom 21.12.1929.

150 StAnz Nr. 9f. vom 13.1.1930f.

151 KB Nr. 15 vom 20.1.1930. Vgl. zur Regierungserweiterung, bei der Bazille kein Thema mehr war, Besson (wie Anm. 3) S.75-83, Matz (wie Anm. 69) S. 66-77, Schnabel, Württemberg (wie Anm.3) S.62-66 jeweils mit starker Betonung der Rolle der DDP. Matz sieht ein Beitrittsmotiv der Demokraten auch im „drohenden Alleingang der DVP“, S.70.

152 StAnz Nr. 41 vom 19.2.1930.

153 StAnz Nr. 109 vom 12.5.1930. 


\section{Die württembergische DVP und die Reichspolitik 1920-1928}

Die Politik der Reichs-DVP kann hier nur am Rande behandelt werden, vielmehr ist die Haltung der Württemberger zu Reichsthemen zu betrachten. Ein solches stellte der Kapp-Putsch vom März 1920 dar, von dem sich die Partei vollständig überrascht zeigte. In einer Erklärung erhob sie schärfsten Einspruch gegen die Zensurmaßnahmen, lehnte jedoch jeden Versuch ab, durch gewaltsamen Bruch der Verfassung die bestehende Regierung zu stürzen. Allerdings bescheinigte sie der Reichsregierung ein gerüttelt Maß von Schuld und forderte Newwablen im Reich und in Württemberg, die Volkswahl des Reichspräsidenten sowie eine Regierungsumbildung mit Fachministern ${ }^{154}$. Dieser Standpunkt korrespondierte mit der dubiosen Rolle Stresemanns ${ }^{155}$.

Zur Reichstagswahl vom Sommer 1920 hatte Bickes Stresemann gebeten, den Direktor der Deutschen Bank, von Stauß, zur Kandidatur in Württemberg zu bewegen, obwohl man sich in Berlin einig war, dass der in den Anfängen steckende Landesverband kaum Chancen zur Erringung eines Mandates hätte. Dessen Bewerbung blieb dann auch erfolglos; der Misserfolg sei zudem wohl mit der unglücklichen Kandidatur eines Bankdirektors zu begründen ${ }^{156}$.

Ende Juni 1922 beteiligte sich die DVP an einer überparteilichen Trauerkundgebung für den ermordeten Außenminister Rathenau in Stuttgart. Bickes führte dort aus, man habe dessen Politik nicht immer zugestimmt, ihm aber nie die Ebrlichkeit seines Willens bestritten ${ }^{157}$.

Bei der Reichstagswahl vom 4. Mai 1924 konnte er, unterstützt durch einen Auftritt Stresemanns in Stuttgart - der Riesensaal der Liederhalle war von Tausenden überfüllt ${ }^{158}$ - erstmals ein Mandat erringen. Bis 1930 blieb er der einzige Vertreter der württembergischen DVP im Reichsparlament. Bei der für den 7. Dezember anberaumten zweiten Reichswahl des Jahres $1924^{159}$ trat die Reichs-DVP mit dem Ziel einer Einbeziehung der DNVP in die neue Regierung an und bezichtigte zugleich die DDP, die Schuld am Scheitern der alten Regierung zu tragen. Diesem Kurs schlossen sich die Württemberger, ungeachtet früherer Kritik an den Deutschnationalen, vorbehaltlos an und stellten fest, die Haltung der DDP habe

154 Hohenloher Bote (Öhringen), Nr. 66 vom 19.3.1920.

155 Vgl. dazu ausführlich Richter, Die Deutsche Volkspartei (wie Anm. 1) S. 90-106. Zur denkbaren Kritik von Bickes vgl. ebd., S. 104, Anm. 56.

156 Eberhard Kolb/Ludwig Richter (Bearb.), Nationalliberalismus in der Weimarer Republik: Die Führungsgremien der Deutschen Volkspartei 1918-1933, Bd.1, Düsseldorf 1999, S. 288 und 305f. ( = Sitzungen des Geschäftsführenden Reichsausschusses vom 17.4. und 16.6.1920).

157 KB Nr. 150 vom 30.6.1922.

158 KB Nr. 104 vom 3.5.1924. Eine Wahlrede von Bickes in Hall wurde oben bereits behandelt.

159 Vgl. dazu Richter, Die Deutsche Volkspartei (wie Anm. 1) S. 348 f. 
bereits zum Übertritt demokratischer Abgeordneter zu DVP geführt. Bickes wurde erneut als Spitzenkandidat nominiert ${ }^{160}$.

Das schon erwähnte Wahlflugblatt der württembergischen Nationalliberalen warb dann neben Mittelstandsforderungen mit nationalen Parolen: Demokraten und SPD wurde Kriecherei um die Gunst des Auslandes vorgeworfen, die DVP als realpolitische Mittelpartei wolle rein deutsche Wablen ${ }^{161}$. In einer Wahlrede in Gaildorf sang Rath ein Loblied auf die vielfältigen Leistungen und den Mut Stresemanns, artikulierte ebenfalls Forderungen des Mittelstandes und plädierte unter Vorbehalten für den Eintritt in den Völkerbund, an den er die Hoffnung auf Rückgabe der Kolonien knüpfte ${ }^{162}$. Bickes konnte erwartungsgemäß sein Mandat behaupten, die Partei hatte in Württemberg einen Zuwachs von etwa 14.000 Stimmen erzielt. Auch die Reichspartei hatte die Zahl ihrer Sitze von 45 auf 51 steigern können ${ }^{163}$.

Während die Landespartei im Januar 1925 einen flammenden Protest gegen den schnöden Vertragsbruch der Entente wegen der Nichträumung Kölns erhob ${ }^{164}$, trat einige Wochen später die Wahl eines neuen Reichspräsidenten in den Mittelpunkt des allgemeinen Interesses. Nach der nicht unproblematischen Nominierung des Duisburger Oberbürgermeisters Jarres von der DVP, hinter dem auch die Deutschnationalen standen ${ }^{165}$, übte Bickes sogar Kritik: In Süddeutschland habe man den Eindruck, die Parteileitung sei „zu voreilig“ gewesen ${ }^{166}$. Wenig später sprach sich die Landespartei jedoch für die Sammlung der beiden Parteien im sogenannten Reichsblock und für Jarres aus ${ }^{167}$.

Nachdem Jarres, der auch in Stuttgart aufgetreten war, im ersten Wahlgang am 29. März die absolute Mehrheit verfehlte und eine erneute Kandidatur abgelehnt hatte, telegraphierte ihm der württembergische Landesausschuss, schmerzlich berübrt zu sein ${ }^{168}$. Nach einem Hin und Her im Reichsausschuss sprach sich schließlich auch die Reichs-DVP für die von den Deutschnationalen forcierte Kandidatur Hindenburgs aus, die auch von den Württembergern unterstützt wurde. Allein Egelhaaf veröffentlichte im „Merkur“ sechs Artikel ${ }^{169}$, in einer Gaildorfer Anzeige warb die DVP gemeinsam mit den Deutschnationalen, dem Bauernbund und der

160 Vertreterversammlung der DVP, KB Nr.253 vom 27.10.1924. - Zu den Überläufern gehörte der in Württemberg geborene Otto Keinath, der später in der württembergischen DVP noch eine Rolle spielen sollte.

161 Wie Anm. 54.

162 KB Nr. 272 vom 18.11.1924.

${ }^{163}$ Zum Ergebnis in Württemberg KB Nr. 290 vom 9.12.1924, zur Reichspartei Richter, Die Deutsche Volkspartei (wie Anm. 1) S. 333 und 358.

164 KB Nr. 15 vom 20.1.1925.

165 Vgl. dazu Richter, Die Deutsche Volkspartei (wie Anm. 1) S. 366-389.

166 Ebd., S. 374, Anm. 35.

167 Versammlung in Gaildorf, KB Nr. 69 vom 24.3.1925.

$168 \mathrm{~KB}$ Nr. 87 vom 16.4.1925.

169 Egelhaaf (wie Anm. 7) S. 172. 
NSDAP für den ueber den Parteien stehenden getreuen deutschen Eckhardt ${ }^{170}$. Der knappe Sieg Hindenburgs befriedigte eigentlich nur den rechten Flügel der DVP ${ }^{171}$ und markierte eine Zäsur in der Entwicklung der Republik.

Seit 1924 artikulierten die württembergischen Nationalliberalen mehrfach die Aufwertungsfrage - wohl primär als Bestandteil ihrer Mittelstandspolitik. Der geschäftsführende Ausschuss forderte etwa, wie es Moral und Gerechtigkeit verlangten, den entrechteten Gläubigern ihre Rechte zu gewähren. Der Aufwertungsausschuss des Reichstages wurde kritisiert; mit Zinszahlungen müsse baldigst begonnen werden ${ }^{172}$. Ein knappes Jahr später erläuterte Bickes, im Reichstag habe man Rechtsauffassung und Wirtschaftserwägung in Einklang bringen müssen ${ }^{173}$. 1926 referierte ein Leipziger Abgeordneter vor dem Stuttgarter Parteitag, bei dem Kompromiss der Aufwertungsgesetze hätten andere noch weniger als seine Partei erreicht und gestand deren Unbilligkeiten zu, lehnte den Plan eines Volksentscheides jedoch $\mathrm{ab}^{174}$.

Die Befürwortung und Unterstützung der Politik Stresemanns blieb das Credo der württembergischen DVP. So warb Bickes etwa für die Außenpolitik des Parteiführers und insbesondere für Locarno ${ }^{175}$, Egelhaaf kritisierte die zwiespältige Regierungshaltung zu diesem Thema im Landtag ${ }^{176}$, ähnlich äußerte sich auch der geschäftsführende Landesausschuss ${ }^{177}$. Schließlich betonte Rath, man halte an der Locarnopolitik unbedingt fest ${ }^{178}$. Während die abtrünnigen Deutschnationalen von Bickes scharf kritisiert wurden ${ }^{179}$, stellte der Reichstagsabgeordnete Rheinbaben auf dem DVP-Landesparteitag unter Beifall fest, von einer Stuttgarter Rede Strese-

170 KB Nr. 93 vom 23.4.1925. 389.

171 Vgl. zum zweiten Wahlgang Richter, Die Deutsche Volkspartei (wie Anm. 1) S. 377-

172 KB Nr. 248 vom 21.10.1924. - Auch im Flugblatt zur zweiten Reichstagwahl 1924 wurde dies thematisiert. Wie Anm. 54.

173 Sitzung des Landesausschusses, KB Nr. 224 vom 25.9.1925.

174 KB Nr. 90 vom 20.4.1926. Vgl. zu dem komplexen Thema Richter, Die Deutsche Volkspartei (wie Anm.1) mit Literaturangaben, S.395f. - Die Haltung der DVP war wohl zusätzlich durch die im Entstehen begriffene Volksrechtspartei motiviert, die sich der Aufwertungsfrage besonders widmete. Vgl. dazu eine ablehnende Anzeige in den Wahlnachrichten Nr. 3 vom 18.5.1928.

175 Versammlung in Crailsheim, KB Nr. 252 vom 28.10.1925.

176 Nach KB Nr.290 vom 11.12.1925 (Landtag vom 10.12.1925).

177 KB Nr. 9 vom 13.1.1926.

178 Landtag vom 26.3.1926, S. 2255-2261. - In den auf Initiative Stresemanns in Locarno im Oktober 1925 vereinbarten Abkommen verzichteten Belgien, Frankreich und Deutschland auf eine gewaltsame Änderung der jetzigen Grenzen, Großbritannien und Italien fungierten als Garantiemächte. Das auch Schiedsverträge mit Polen und der Tschechoslowakei umfassende Vertragswerk stellte „eine bedeutsame Station auf dem Weg zur internationalen Rehabilitierung Deutschlands" dar. Vgl. zu den Verträgen und ihren Folgen - dem Austritt der DNVP aus der Reichsregierung - Richter, Die Deutsche Volkspartei (wie Anm.1) S. 402-407, Zitat S. 403.

179 DVP-Tagung in Heilbronn, KB Nr. 257 vom 3.11.1926. 
manns 1923 über die Liquidierung der Rubrbesetzung bis Locarno gebt eine einzige gerade Linie ${ }^{180}$. Schließlich erklärte Rath am 4.11.1927 im Landtag, Stresemanns Außenpolitik ${ }^{181}$ sei Allgemeingut geworden. Zugleich lehnte er, die Haltung des Außenministers unterstützend, ein Ostlocarno ab ${ }^{182}$.

Ein großes politisches Thema war 1926 die Frage der Fürstenenteignung. Auf dem Landesparteitag erklärte ein Reichstagsabgeordneter unter starkem Beifall, der Volksentscheid auf völlige Enteignung sei eine Brutalität ${ }^{183}$, der Reichsausschuss konstatierte einen Verstoß gegen Moral, Recht und Verfassung ${ }^{184}$. Daraufhin bedauerte der württembergische Landesausschuss, dass eine geschlossene Front der bürgerlichen Parteien gegen den bolschewistischen Anschlag gescheitert sei und forderte in Übereinstimmung mit der Reichspartei die Mitglieder auf, nicht abzustimmen ${ }^{185}$. In Allianz mit der DNVP und dem Bauernbund warben die Württemberger für den Abstimmungsboykott; es gehe um die Frage Rechstaat oder Raubstaat ${ }^{186}$ und trugen so zum Misserfolg der von KPD und SPD getragenen Initiative bei.

Als der erfolglose Bewerber um die Reichspräsidentschaft, Karl Jarres, im Juli 1926 im Verein mit dem Deutschnationalen von Gayl zur Bildung einer reichsweiten Arbeitsgemeinschaft von DVP und DNVP aufrief, bewies Bickes erneut seine Gefolgschaft zu Stresemann, der sich strikt gegen das Projekt stellte, während es vom hessischen Vorsitzenden Dingeldey begrüßt wurde - angeblich stoße es in Süddeutschland auf geschlossene Zustimmung. Bickes widersprach in einem Schreiben an die Reichsgeschäftstelle vehement: In Württemberg wie in Baden werde die Arbeitsgemeinschaft klar abgelehnt ${ }^{187}$. Seine Haltung war konsequent, kritisierte er doch die DNVP im November 1926 scharf ${ }^{188}$.

Zu den Reichstagswahlen im Mai 1928 warb die Reichs-DVP mit dem Slogan Was gehen Dich die andern an, Du wäblst wie Gustav Stresemann. In ihren „Wahlnachrichten“ setzten die Württemberger dann auch ganz auf ihren vom Parteipolitiker längst zum Staatsmann gereiften Vorsitzenden, dessen Außenpolitik seit 1923 von der überwiegenden Mebrbeit bejaht und der als Führer des deutschen Volkes betrachtet werde. Er habe die geschichtliche Aufgabe übernommen, die Erneuerung und Festigung des Reiches durchzuführen ${ }^{189}$.

180 KB Nr. 90 vom 20.4.1926.

181 Dazu gehörte auch der Beitritt zum Völkerbund, in dem Rath die volkswirtschaftlich wichtigste Frage sah. Versammlung in Gaildorf, KB Nr. 272 vom 18.11.1924.

${ }^{182}$ Landtag vom 4.11.1927, S. 4306-4311.

183 KB Nr. 90 vom 20.4.1926.

184 KB Nr. 117 vom 22.5.1926.

185 KB Nr. 124 vom 1.6.1926.

186 Anzeige im Hohenloher Boten Nr. 140 vom 19.6.1926. - Vgl. zum Gesamtkomplex Richter, Die Deutsche Volkspartei (wie Anm. 1) S. 418-429.

187 Vgl. Richter, Die Deutsche Volkspartei (wie Anm. 1) S. 436f., Anm. 32. Zu Verlauf und Scheitern der Initiative ebd., S. 430-441.

188 Rede in Heilbronn, KB Nr. 257 vom 3.11.1926.

189 Ganzseitige Huldigung zu Stresemanns 50. Geburtstag, Wahlnachrichten Nr. 3 vom 
Der vom Zentralvorstand formulierte Wahlaufruf betonte die außenpolitische Verständigungspolitik. Gleichzeitig wurden jedoch die völlige Befreiung der Rheinlande, die Rückgabe des Saargebietes, die Beseitigung der unmöglichen Ostgrenze, erträgliche Reparationsleistungen und das Recht zu kolonialer Betätigung gefordert. Innenpolitisch habe die Partei in der Regierung im Sinne des Wiederaufbaus gewirkt, sie werde dem Mittelstand wie bisher besondere Fürsorge entgegen bringen und fühle sich der sozialen Gesetzgebung verpflichtet. Zum an überspannte(n) klerikale(n) Forderungen gescheiterten Reichsschulgesetz und damit der Koalition wurde die Parteihaltung erläutert. Man habe, je nach regionalen Wünschen und Traditionen, sowohl die konfessionelle als auch die christliche Simultanschule befürwortet ${ }^{190}$.

Der wiederum als Spitzenkandidat nominierte Bickes forderte die Reform des Parlamentarismus und damit eine Änderung der Reichsverfassung. Er begründete dies mit dem ohne Korrektiv gebliebenen Übermaß von Machtfülle des Reichstags, dessen Parteien verantwortungslos nur noch auf kostspielige volkstümliche Beschlüsse zielten. Auch seine Mitkandidaten Keinath, Groß und Rendle hatten Beiträge verfasst. Ersterer beklagte übereinstimmend mit Bickes die Steuerüberlastung, gegen die seine Partei stets gekämpft habe. Der Stuttgarter Verbandssekretär Philipp Groß betonte als Arbeitnehmervertreter den Charakter der DVP als Volkspartei, die keine Klasseninteressen vertrete. Sie umfasse zwar alle Stände, besitze aber allseitiges Verständnis für die Nöte der Arbeitnebmerschichten. Malermeister Rendle aus Heilbronn agitierte gegen die einseitige Interessenpolitik der Splitterparteien und rief seinen Standesgenossen zu, die DVP werde ihrer Grundauffassung entsprechend auch in Zukunft dem gewerbetreibenden Mittelstand besondere Aufmerksamkeit schenken ${ }^{191}$.

Natürlich kritisierten die „Wahlnachrichten“ auch die übrigen politischen Konkurrenten. So wurde der DDP Linksdrall und starke Abbängigkeit von der SPD bescheinigt. Zudem habe die Partei beim Neubau eines Panzerkreuzers schwächliche (n) Pazifismus gezeigt, für den in Württemberg das Verständnis fehle. Schließlich seien die Demokraten altersgrau, während die DVP junge Kräfte mobilisiert habe $^{192}$. Deutschnationale und Nationalsozialisten sahen die Nationalliberalen in

18.5.1928. Dort auch der Wahlslogan, der als Plakat auf dem Umschlag des Richter-Buches abgebildet ist. Stresemann hatte für das Wahlblatt einen Beitrag geschrieben, in dem er sein Streben als nationale Realpolitik bezeichnete und betonte, das Reich werde ohne die DVP den größten Schwankungen ausgesetzt sein.

190 Wahlnachrichten Nr. 1 vom 10.5.1928 (z.T. in Fettdruck). - Die württembergischen Nationalliberalen hatten sich vielfach mit dem Schulgesetz und seinen landespolitischen Auswirkungen beschäftigt. Vgl. dazu KB Nr. 224 vom 25.9.1925, StAnz Nr. 261 vom 8.11.1927 (Landtagsrede von Rath), StAnz Nr. 290 vom 16.12.1927, StAnz Nr. 33 vom 9.2.1928 (Landtagsrede von Hartmann).

191 Wahlnachrichten Nr. 1 vom 10.5.1928.

192 Wahlnachrichten Nr. 3 vom 18.5.1928. - Als Indiz einer Verjüngung mag die Grün- 
geistiger Beschränktheit vereint ${ }^{193}$. Ihr stark auf Stresemann fixiertes Programm sollte die gesamte potentielle Klientel ansprechen, indem es neben nationalen auch mittelständische und sozialpolitische Ziele betonte. Hoffnungsvoll hatte man postuliert: Die Volkspartei muß diesmal siegen ${ }^{194}$.

Das Ergebnis war dann jedoch enttäuschend. Während SPD und KPD Gewinne erzielten, hatte das bürgerliche Lager Verluste eingefahren. Die Reichs-DVP verlor gegenüber den Dezemberwahlen von 1924 etwa 370.000 Stimmen $^{195}$, ihr württembergischer Landesverband konnte wiederum nur einen Vertreter - Bickes - nach Berlin entsenden.

Dessen Rolle im Reichstag war und blieb die eines Hinterbänklers, der in seinen wenigen Reden keine ,großen Themen' behandelte. Er bejahte 1925 die Bestrebungen gegen den Alkoholmissbrauch, bei der Beratung des Gaststättengesetzes 1930 kam er darauf zurück und begrüßte dessen gesundheitliche und ethische Ziele. 1927 plädierte er für die Bekämpfung der Geschlechtskrankheiten und - an DRK-Zielen orientiert - forderte er eine Anstalt zur Bekämpfung der Säuglingssterblichkeit und wollte eine Reform des Krankenpflegewesens ${ }^{196}$.

\section{Im Zeichen der Parteien-, Staats- und Wirtschaftskrise 1929/1930-1932}

Dass Stresemanns Gegner, vor allem die Deutschnationalen, ihn nahezu permanent bekämpften und diffamierten war politischer Alltag. Dass jedoch seine Widersacher in der eigenen Partei ihm das Leben verbitterten, gehörte zu seiner persönlichen Tragik - und der der DVP. Bereits 1924 schrieb er, es scheine das Schicksal nationalliberaler Führer zu sein, „weniger“ im Parteienkampf „als unter der seelischen Zermürbung durch die Anfechtungen aus den eigenen Reihen“ zu leiden ${ }^{197}$. Auch Zeitgenossen Stresemanns registrierten diesen Sachverhalt. So schrieb etwa der württembergische Staatspräsident Bolz seiner Frau, der Außenminister sei nicht nur von politischen Problemen, sondern auch von innerparteilichem Widerstand „aufgerieben“ worden ${ }^{198}$. Auch Brüning berichtete über

dung einer DVP-Hochschulgruppe an der Universität Tübingen gelten. Vgl. Schwabenwarte Nr. 9, 1928.

193 Wahlnachrichten Nr. 2 vom 14.5.1928.

194 Ebd.

195 Vgl. zur Wahl und ihren Ergebnissen Richter, Die Deutsche Volkspartei (wie Anm. 1) S. $470-484$.

196 Vgl. zu seinen hier nur unvollständig skizzierten Aktivitäten das Register der Reichstagsprotokolle, ferner KB Nr. 41 vom 19.2.1925, KB Nr. 141 vom 21.6. 1927 (zum Schankstättengesetz), KB Nr. 74 vom 29.3.1930.

197 Zit. nach Erich Eyck, Geschichte der Weimarer Republik, Bd.1, Erlenbach-Zürich/ Stuttgart 1954, S. 341. Vgl. dazu Richter, Die Deutsche Volkspartei (wie Anm. 1).

198 Zit. nach Max Miller, Eugen Bolz. Staatsmann und Bekenner, Stuttgart 1951, S. 357. 
„Herren vom Rechtsflügel der DVP“, die Stresemanns Leben „bis in den Tod hinein verbittert hatten “199.

Stresemann war entschlossen, diesen unerträglichen Zustand, an dem die Württemberger keinen Anteil hatten, zu beenden und zugleich eine Reform des bürgerlichen Parteiengefüges einzuleiten. Mit seiner zerstrittenen Partei hatte er spätestens seit 1928/1929 „innerlich gebrochen“ 200 und verfolgte den Plan einer neuen Mittelpartei, bestehend aus den „Linken“ der DNVP, den Demokraten und seiner Partei als „Kern“. Damit wären seine Gegner im eigenen Lager als Minderheit praktisch ausgeschaltet gewesen. Zu dieser Strategie gehörte auch die stärkere Einbeziehung der jungen Generation, die sich im Frühjahr 1929 in Reformclubs organisierte und schließlich die Reichsgemeinschaft junger Volksparteiler bildete. Zudem war auch der Jungdeutsche Orden Teil dieser Überlegungen. Da die Hugenberg-Gegner in der DNVP zögerten, stellte die rasche Fusion mit der DDP das vordringliche Ziel dar. Die der Öffentlichkeit verborgenen Aktivitäten kulminierten im September 1929 in Gesprächen Stresemanns mit dem demokratischen Parteiführer Koch-Weser. Dabei wurde die Bildung eines „Blocks“ vereinbart, dem dann die Fusion folgen sollte. Das von beiden Seiten mit Energie verfolgte Projekt, bei dem Stresemann sogar bereit war, die Frondeure in seiner Partei auszuschließen, scheiterte mit seinem $\operatorname{Tod}^{201}$.

Stresemanns Ableben am 3. Oktober 1929 „nahm symbolhaft den Tod der Repu-

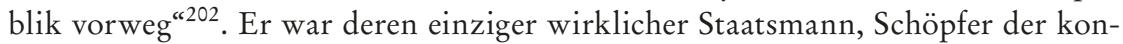
struktiven Außenpolitik und Architekt fast aller Koalitionen und hinterließ so ein nicht mehr zu füllendes Vakuum. Dies galt ganz besonders für seine Partei, die unter den überforderten Nachfolgern Scholz und Dingeldey ${ }^{203}$ nach rechts driftete.

Die württembergischen Nationalliberalen verloren mit Stresemann ihr bewundertes Idol. Während einer Gedenkfeier rühmte Bickes den früh Verstobenen, er sei nie Parteimann im üblichen Sinne gewesen, sein Wirken habe dem Wiederaufstieg des Vaterlandes gegolten. Als Vermächtnis habe er den Gedanken der Volksgemeinschaft postuliert und versucht, die Brücke zwischen Vergangenheit und Gegenwart zu schlagen. Das von ihm Geleistete werde erst die Nachwelt wirklich ermessen können ${ }^{204}$.

Die oben geschilderten Bestrebungen Stresemanns um eine Parteifusion fanden auch Resonanz in Württemberg. Dazu gehörte die Gründung eines Jungliberalen Clubs in Stuttgart im März 1929, der sich neben der staatsbürgerlichen Bildung

199 Heinrich BRÜNING, Memoiren 1918-1934, Stuttgart 1970, S. 175.

200 Richter, Die Deutsche Volkspartei (wie Anm. 1) S. 550.

201 Ausführlich dazu ebd., S. 550-565.

202 Helmut Heiber, Die Republik von Weimar, München 1971, S. 206.

203 BRÜNING (wie Anm. 199) S. 205, 234 charakterisierte ihn als Intriganten.

204 Die vom Stuttgarter Ortsverein ausgerichtete Feier wurde aus allen Bevölkerungskreisen besucht, auch Regierungsvertreter waren anwesend, StAnz Nr. 268 vom 14.11.1929. Ausführlich gew ürdigt wurde er auch in der Schwabenwarte, deren Nr. 41 vom 12.10.1929 fast gänzlich dem Andenken Stresemanns gewidmet war. 
auch die liberale Einigung zum Ziel gesetzt hatte. Der Club war Teil des Stuttgarter Ortsvereins, bot Vorträge und Diskussionen und trug einen „volksparteilichen Charakter“205. Auch die schon erwähnte Landtagsrede von Rath im April 1929 sprach, offenbar auf Stresemanns Fusionspläne anspielend und diese gutheißend, von einer möglichen neue(n) Partei und setzte ebenfalls auf die reformwillige Jugend $^{206}$. Schließlich darf auch der schon behandelte Regierungseintritt von DVP und DDP letztlich als Ausfluss und Nachwirkung der Bestrebungen Stresemanns gesehen werden.

Den von Rath im Januar 1930 konstatierten vielfachen Krisenerscheinungen im staatlichen, wirtschaftlichen und sozialen Leben des Reiches ${ }^{207}$, die er im Juni 1931 von überall drohenden Sturmzeichen, zurückgehenden Steuererträgen, Kapitalflucht und einem verschlechterten Arbeitsmarkt begleitet sah und ihn sogar einen Bürgerkrieg befürchten ließ ${ }^{208}$, wollte der Landesvorsitzende mit einer württembergischen Gegenstrategie begegnen. Diese soll hier in Gänze behandelt werden; erst dann ist auf die konkreten Ereignisse zurückzukommen.

Als Voraussetzung dazu sah er zunächst die geordnet(e) Finanzlage Württembergs, die auch für den kommenden Haushalt gelte ${ }^{209}$ und damit einhergehend die voll bejahte „Politik der Sparsamkeit“ der württembergischen Regierung ${ }^{210}$. Rath blieb weiterhin zuversichtlich. Im Januar 1931 betonte er die anhaltende gesunde Finanzpolitik, könnten doch sowohl der Etat von 1930 als auch die Haushalte für 1931 und 1932 obne Defizit, allerdings mit stärkere(n) Abstriche(n) abgeschlossen werden $^{211}$. Trotz fortschreitender Krise sprach auch der Abgeordnete Hartmann noch im April 1932 in einer Wahlrede von verbältnismäßig guten Finanzverbältnissen in Württemberg und hoffte, dass von hier die Gesundung der Verbältnisse einsetzen werde $^{212}$.

Dieser erstaunliche Optimismus hatte eine weitere Komponente. Seit dem Eintritt in die Regierung lobten die württembergischen Nationalliberalen immer wieder sowohl deren Zusammenhalt als auch die gute Zusammenarbeit mit den Demo-

205 Bericht des Generalsekretärs nach Berlin, zit. nach Richter, Die Deutsche Volkspartei (wie Anm. 1) S. 558, Anm. 34.

206 Wie Anm. 144.

207 Rede vor dem Landesausschuss, StAnz Nr. 10 vom 14.1.1930.

${ }^{208}$ Landtag vom 12.6.1931, S. 3758-3761.

209 Wie Anm. 207.

${ }^{210}$ Dazu ausführlich Besson (wie Anm.3) S. 217-250. - Vgl. Raths Stellungnahme zur Gehaltskürzung der Beamten, die er trotz der Kritik von Beamtenverbänden als zu den „Staatsnotwendigkeiten“ gehörend verteidigte. Sitzung des Staatsministeriums vom 30.11.1930. Abgedruckt ebd., S. 392. Bemerkenswert war dabei, dass er Staats- vor Gruppeninteressen setzte und so risikobewusst die zur eigenen Klientel gehörenden Staatsdiener nicht schonen wollte.

${ }^{211}$ Rede in Stuttgart, KB Nr.21 vom 27.1.1931. Auch sein Landtagskollege Dr. Burger betonte wenig später die gesunde Finanzlage und beschwor die Sparsamkeit, Landtag vom 25.2.1931, S.3019-3025.

${ }^{212}$ Fränkischer Grenzbote, Crailsheim (fortan FrGb) Nr. 89 vom 18.4.1932. 
kraten. Im Mai 1930 fand der Vorsitzende der Ortsgruppe Groß-Stuttgart, Bälz, die Regierungsbeteiligung habe sich bewährt und Staatsrat Rath durch Vermittlung beim Landessteuergesetz bereits Verdienste erworben. Man dürfe bis zu den Wahlen 1932 rubige Zustände erwarten ${ }^{213}$.

Die württembergische Gegenstrategie konkretisierte Rath mit der schon im Januar 1930 angedeuteten Formel auf dem DVP-Landesparteitag vom Mai 1931: Das Land müsse die Rolle einer „staatliche(n) Ordnungszelle“ einnehmen ${ }^{214}$. Hintergrund dieser Haltung war schließlich auch die „relativ günstige wirtschaftliche Lage" des Landes ${ }^{215}$ im Vergleich zu den anderen Gliedern des Reiches, auf die hier nicht weiter eingegangen wird ${ }^{216}$. An der Konzeption der „Ordnungszelle“, die letztlich Kennzeichen der von Kanzler Brüning gelobten württembergischen Regierungspolitik war ${ }^{217}$, wurde weiterhin festgehalten. Im Vorfeld der Landtagswahlen von 1932 schrieb Rath, diese würden entscheiden, ob Württemberg auch fernerbin eine Ordnungszelle im deutschen Süden bilden könne ${ }^{218}$.

Während der Vertreterversammlung der DVP im Mai 1930 referierte Bickes über die Reichspolitik. Er zeichnete ein bedrückendes Bild der wirtschaftlichen und sozialen Verhältnisse und wiederholte seine im Wahlkampf 1928 erhobene Forderung nach einer Reform des parlamentarischen Systems. Gleichzeitig formulierte er die Notwendigkeit einer große (n) bürgerliche (n) Partei der Mitte, die sich um die DVP als Kristallisationspunkt gruppieren müsse und für alle ihr Nahestehenden offen sei. Sie dürfe jedoch keineswegs einer einseitige(n) Interessenvertretung dienen, sondern habe bei sich widerstreitenden Interessen zu vermittel ${ }^{219}$.

Für Bickes und die württembergische DVP begann die Kandidaten-Nominierung zu den Reichstagswahlen im September 1930 dann mit einem nicht erwarteten Paukenschlag. Während des Vertretertags Anfang August votierten nur 46 Delegierte für ihn, während 51 Stimmen auf Keinath fielen. Bickes fühlte sich

213 Versammlung der Ortsgruppe, KB Nr. 107 vom 9.5.1930. - Auch Rath sprach sich positiv zur Regierungsbeteiligung aus, vgl. KB Nr. 21 vom 27.1.1931, Nr. 26 vom 2.2.1932.

${ }^{214}$ Zit. nach Besson (wie Anm.3) S. 186 mit Anm. 1. Damit sei, so Besson, der „unitarischen Tradition" der Partei eine Absage erteilt worden.

215 Ebd., S. 185.

216 Als Beleg dafür sei lediglich ein Zeitungsartikel von Wirtschaftsminister Maier vom 25.12.1932 angeführt, der den Titel trug „Warum geht es in Schwaben besser? Kommt und seht! “, Abdruck bei Thomas Schnabel, „Warum geht es in Schwaben besser? “, in: Ders. (Hg.), Die Machtergreifung in Südwestdeutschland, Stuttgart 1982, hier S. 214-218.

${ }_{217}$ Er bezeichnete Württemberg als „Musterbeispiel der Staatsführung, Sparsamkeit und soliden Finanzpolitik für ganz Deutschland“. Zit. nach Miller (wie Anm. 198) S. 394. Vgl. auch BRÜNIng (wie Anm. 199) S. 216.

218 „Um was geht es bei den Landtagswahlen?“, Hohenloher Bote (Öhringen), Nr. 87 vom 15.4.1932.

219 StAnz Nr. 109 vom 12.5.1930 (im Original z.T. gesperrt). 
durch diesem Votum brüskiert und erklärte seinen Austritt aus der Partei; für ihn war dies ein bisher einzig dastehender Fall. Wie der „Staatsanzeiger“ betonte, kam dieses Ergebnis angesichts der Verdienste des Abgewählten für weite Parteikreise und die Öffentlichkeit außerordentlich überraschend ${ }^{220}$. Ein Zeitgenosse gab als Begründung an, man habe in der Partei geglaubt, mit Keinath „einen zugkräftigeren Kandidaten gefunden zu haben“221. In der Tat besaß dieser als Reichstagsmitglied wohl mehr Profil als Bickes. Während letztlich unklar bleibt, ob das Votum einer Initiative des von Besson konstatierten „rechten Flügels“ der Partei ${ }^{222} \mathrm{zu}$ verdanken war, steht doch fest, dass der Vorgang als Krisenerscheinung und Aderlass zu werten ist ${ }^{223}$. Ein Kommentar im „Merkur“ suchte die Dinge zu relativieren. Er nannte die Abwahl des um die Partei Verdienten in Zeiten, die Geschlossenheit erforderten, zwar unverständlich, erwähnte jedoch auch Forderungen nach einer Parteiverjüngung - Keinath war etwa 11 Jahre jünger als Bickes. Letztlich sah das Blatt in der Abwahl ein Zufallsergebnis und äußerte die - unerfüllte - Hoffnung auf eine Rückkehr ${ }^{224}$.

Als ob nichts geschehen wäre widmete man sich nun den Wahlen. Ein außerordentlicher Vertretertag bestätigte gegen eine kleine Minderheit einen zuvor gefassten Beschluss, mit den inzwischen im Reich als Staatspartei firmierenden Demokraten ein Wahlabkommen abzuschließen, das sowohl Programm als auch Selbständigkeit beider Seiten wahre. Nachdem eine solche Einigung auf Reichsebene gescheitert war, äußerte man zwar Verständnis für die ablehnende Haltung der nicht kontaktierten Parteiführung, begründete den Schritt jedoch mit den besonderen Verbältnissen Württembergs und den Bedürfnisse(n) der Landespolitik. Zudem wurde betont, eine gesamtbürgerliche Sammlung sei notwendiger als je zuvor $^{225}$.

Die auch Baden einbeziehende „linke“ Weichenstellung brachte wenig später die Einigung auf in beiden Ländern zu präsentierende und miteinander verbundene Einheitslisten. Die württembergische Liste trug die Namen Theodor Heuß für die Staats- und Keinath für die Volkspartei. Der Schritt wurde mit der Parole nicht Interessenpolitik, sondern Staatspolitik, nicht Zersplitterung, sondern Sammlung begründet ${ }^{226}$. Ungeachtet der Skepsis der Parteiführung begrüßte der Mitstreiter Stresemanns und Parteisenior Kahl das Bündnis mit herzlicher Frende und hoffte, dass so sein Ideal einer Wiederaufrichtung einer großen deutschen liberalen Partei

220 StAnz Nr. 179 vom 4.8.1930 mit Austrittsschreiben und Kommentar.

221 Leopold Hegelmaier, Beamter und Soldat 1884-1936. Lebenserinnerungen, Stuttgart 1937, S. 309.

222 Besson (wie Anm. 3) S. 76.

223 Auch der Abgang des verdienten Generalsekretärs Maerz im Vorjahr (Schwabenwarte Nr. 25, 1929) war ein Verlust für die Partei.

${ }^{224}$ Merkur Nr. 179 vom 5.8.1930.

${ }^{225}$ StAnz Nr. 188 vom 14.8.1930. Vgl. auch Richter, Die Deutsche Volkspartei (wie Anm. 1) S. 662.

226 StAnz Nr. 190 vom 16.8.1930. 
näher gerückt sei ${ }^{227}$. Auch Keinath setzte große Hoffnungen auf den Sammelruf. Er sah Chancen für alle tüchtigen Kräfte und auch Rettungsmöglichkeiten für Wirtschaft, Staat und Kultur ${ }^{228}$. Drastisch formulierte eine gemeinsame Wahlanzeige: Wer nicht will dass alles zusammengehanen wird, wer will, dass Deutschland wieder groß wird durch Sparsamkeit und Ordnung müsse die Einheitsliste wählen ${ }^{229}$.

Die großen Erwartungen beider Seiten wurden enttäuscht. Keinath und Heuß zogen zwar in den Reichstag ein, so dass für die württembergische DVP der Stand von 1924 und 1928 erhalten blieb, während die Reichspartei nur noch 30 Mandate erreichte. Zusammen erzielten die beiden Parteien jedoch etwa 37.000 Stimmen weniger als $1928^{230}$. Damit war deutlich geworden, dass das Bündnis keine Zukunftsperspektive darstellte. Dennoch betonte der Landesausschuss der DVP, man werde auch künftig ein enges Einvernehmen mit der Staatspartei pflegen. Zugleich reagierte man auf den alarmierenden Sieg der NSDAP, die 107 Mandate gewonnen hatte - 1928 waren es 12 gewesen. Nun müsse Kanzler Brüning im vollen Ernst mit der Partei über ihre Regierungsbeteiligung verhandeln. Dort würde sie wohl ihr Programm wesentlich abschwächen. Dieser Schritt sei das beste Hilfsmittel, um diese nationalsozialistische Welle zum Abebben zu bringen. Dagegen wurde eine Aufnahme der SPD in die Reichsregierung abgelehnt ${ }^{231}$. An dieser Haltung wird deutlich, dass die württembergischen Nationalliberalen den wahren Charakter der Hitler-Partei nicht durchschauten - ein Manko, das sie letztlich mit dem gesamten bürgerlichen Lager teilten.

Wohl als Reaktion auf die sich in Berlin dahinschleppenden Parteiverhandlungen ${ }^{232}$ und auch als später Reflex auf die vorjährige Reichstagswahl schrieb Rath im September 1931 einen langen Zeitungsartikel ${ }^{233}$. Auffällig war, dass er in seinem Mahnruf die Wirtschaftskrise eigentlich nur als Folge unserer Partei- und Parlamentsverbältnisse sah. Die schon so häufig kritisierte Unzabl von Parteien produziere insbesondere im Reichstag verantwortungslos eine Flut von Einzelinteressen verfolgenden Anträgen auf Kosten der Allgemeinheit. Diesem hemmungslosen Parlamentarismus fast ohne Korrektiv, zu dem noch schwere Tributleistungen träten, gelte es zur Lösung der Finanzmisere auszumerzen, den Blick auf das Ganze zu

227 Gemeinsame Wahlversammlung der beiden Parteien in Stuttgart, StAnz Nr. 206 vom 4.9.1930.

228 Stuttgarter Wahlversammlung, KB Nr. 209 vom 8.9.1930.

229 KB Nr. 214 vom 13.9.1930.

230 StAnz Nr. 215 vom 15.9.1930. Das Stuttgarter Neue Tagblatt meinte, Volksdienst und Wirtschaftspartei hätten von diesem Verlust gewaltig profitiert, Wahlkommentare im StAnz Nr.216 vom 16.9.1930.

231 StAnz Nr. 234 vom 7.10.1930.

232 Vgl. dazu vor allem Larry Eugene Jones, Sammlung oder Zersplitterung? Die Bestrebungen zur Bildung einer neuen Mittelpartei in der Endphase der Weimarer Republik 19301933, in: Vierteljahrshefte für Zeitgeschichte 3 (1977) S. 265-304.

233 „Abbau der Zahl der politischen Parteien!“, KB Nr.228 vom 30.9.1931 (Titelseite). Daraus das Folgende. 
richten und statt Parteipolitik wirklich vaterländische Arbeit zu leisten. Besonders in den Mittelparteien müsse ein Umdenken erfolgen, das zu einer umfassenden Arbeitsgemeinschaft führe. Dabei gelte, dass neben Deutschnationalen und SPD kein Raum für die politischen Exerzitien von 6-10 Parteien bleibe. Unter Berufung auf Stresemann beschwor er dessen Vision einer großen Deutschen Mittelpartei, die ja auch Bickes im Mai des Vorjahres gefordert hatte.

Dazu sah Rath in Württemberg, wo in Regierung und Landtag die parteipolitischen Differenzen mehr und mehr verflacht seien, eine beispielhafte Entwicklung - eben die „Ordnungszelle“. Angesichts des durch Bolschewismus und Marxismus und den Nationalsozialismus bedrohten Mittelstandes forderte er gemeinsame Anstrengungen zur Krisenüberwindung, sah allerdings auch die Anziehungskraft der Hitlerbewegung für bürgerliche Kreise. Während er Letzterer manch gute (n) Kern in nationaler Hinsicht bescheinigte, sah er in ihrem Wirtschaftsprogramm starke sozialistische Gedankengänge ${ }^{234}$, in sozialen Fragen die Teilnahme an den Uebersteigerungen der letzen Jahre. Für einen etwaigen Zerfall der heterogenen NSDAP sagte er - nicht unbedingt logisch argumentierend - Abwanderungen zu den Kommunisten voraus. Zutreffend konstatierte er den Verlust großer Teile der bürgerlichen Jugend an den Nationalsozialismus. Die von ihm geforderte starke Mittelpartei sollte neben das Zentrum treten und so in den Parlamenten eine Kräfteverlagerung zur Mitte bewirken. Damit werde der Glaube an eine Besserung befördert und dem verbreiteten Pessimismus entgegengetreten. Schließlich gehe es um den Bestand des bürgerlichen Staates und so ums Ganze.

Nach den Wahlen von $1930 \mathrm{kam}$ in der Reichs-DVP ein „immer sichtbarer werdender Auflösungsprozeß “ in Gang ${ }^{235}$. Dingeldey war es gelungen, den erfolglosen und kranken Vorsitzenden Scholz zunächst zu demontieren und schließlich im November 1930 in einem „Putsch“ (Ludwig Richter) sowohl den Parteivorsitz als auch die Führung der Reichstagsfraktion zu entwinden ${ }^{236}$. Der von ihm forcierte Rechtskurs, ablesbar etwa an der Wiederannäherung an den Stahlhelm und damit an die in Harzburg formierte "Nationale Opposition“, der beginnenden Abwendung von der Regierung Brüning, Kontakten mit Hitler und an den im April 1931 veröffentlichten „Kampfzielen“ der Partei mit wirtschaftsfreundlichen und dezidiert nationalen Forderungen ${ }^{237}$. Diese Weichenstellungen führten dann zum Verlassen der Regierung Brüning im Herbst 1931. Der Kurs Stresemanns war damit endgültig verlassen, die Partei zu „einem unbedeutenden Anhängsel“ der DNVP geworden $^{238}$, die, innerlich zerrissen, nach einem neuen Standort suchte ${ }^{239}$.

234 Ähnlich hatte er am 21.2.1931 im Landtag (S. 2951-2960) argumentiert und die kapitalistische Wirtschaftsform verteidigt.

${ }^{235}$ Richter, Die Deutsche Volkspartei (wie Anm. 1) S. 676.

236 Ebd., S. 688 f.

${ }^{237}$ Dazu ebd., S. 702-712.

238 Ebd., S. 726.

239 Ausführlich zur hier nur skizzierten Entwicklung ebd., Kapitel 45-48. 
Die Frage, wie sich der württembergische Landesverband zu dieser dramatischen Entwicklung verhielt, ist eindeutig zu beantworten. Auch er ging, letztlich ja ohne wirkliche Alternative, mit Dingeldey auf neuen Kurs. Schon während einer Sitzung des Landesausschusses Ende Juni 1931 wurden Dingeldey und Keinath Dank und Anerkennung für ihr Wirken ausgesprochen ${ }^{240}$. Während 50 Mitglieder der Reichsvereinigung junger Volksparteiler Stuttgart die Parteileitung im Oktober aufforderten, dahin zu wirken, dass die „positiven Kräfte auf der Rechten in den Dienst des Staates“ träten ${ }^{241}$, plädierte die Ortsgruppe Stuttgart fast gleichzeitig für Sanktionen gegen diejenigen Reichstagsabgeordneten, die gegen Dingeldey opponiert hatten ${ }^{242}$.

Insgesamt war eine starke Verunsicherung im bürgerlichen Lager unübersehbar. Während NSDAP und KPD das Land mit Versammlungen geradezu überzogen, besaßen solche der Bürgerlichen fast Seltenheitswert ${ }^{243}$. Zudem hatten sie bei den Gemeinderatswahlen am Jahresende starke Verluste erlitten. In Stuttgart war der Stimmenanteil der bürgerlichen Einheitsliste um mebr als die Hälfte gesunken, während die NSDAP der große Gewinner war ${ }^{244}$.

Die Vertreterversammlung der württembergischen DVP Ende Januar 1932 versuchte im Vorfeld der kommenden Landtagswahlen, bei denen man selbständig agieren wolle, Zuversicht zu vermitteln. Dem zum Spitzenkandidaten nominierten Rath wurde, ebenso wie Keinath, uneingeschränktes Vertrauen ausgesprochen. Während der Landesvorsitzende das Zusammenwirken der Koalition wiederum lobte, beschäftige er sich vornehmlich mit der Reichspolitik. Er motivierte die Abkehr von Brüning mit der Feststellung, dessen Regierung sei mit fast allen ibren Maßnabmen zu spät gekommen, wenn bereits ein Trümmerfeld vorbanden war. Versöhnlich betonte er jedoch, dessen Kabinett dürften dann keine Schwierigkeiten bereitet werden, wenn es sich in einem schweren außenpolitischen Waffengang befinde. Er kritisierte die nationalsozialistische Wirtschafts- und Steuerpolitik, betonte jedoch, diese große Partei von der Mitverantwortung auszuschließen steigere nur ibren Auftrieb. Schließlich gelte es, sich kraftvoll um Hindenburgs Wiederwahl zu bemühen.

240 StAnz Nr. 148 vom 29.6.1931.

${ }^{241}$ Zit. nach Richter, Die Deutsche Volkspartei (wie Anm. 1) S. 721 mit Anm. 47. - Diesem Schritt war ein an Dingeldey gerichtetes Exposé vom 5.8.1931 vorangegangen, das aus der Feder des Schriftführers der Stuttgarter jungen Volksparteiler, Erich Wild, stammte und die dort herrschende Stimmung illustriert. Wild forderte die sofortige Etablierung einer Regierung mit stärkster nationaler Gesinnung. Zu deren Aufgaben sollte etwa die Auflösung der KPD, die ,Domestizierung' der SPD und die Stellung der Berliner Asphaltpresse unter Staatsaufsicht gehören. Zudem forderte der Heißsporn, die nationalen Verbände sollten als staatliche Hilfsorgane, die SS als bewaffnetes Exekutionsorgan fungieren. Abdruckt bei Döнn (wie Anm. 51) S. 437-439. Vgl. auch ebd., S. 227 mit Anm. 921 f.

${ }^{242}$ Vgl. Richter, Die Deutsche Volkspartei (wie Anm. 1) S. 727 mit Anm. 1.

243 Vgl. Schnabel, Württemberg (wie Anm.3) S. 95.

${ }^{244} \mathrm{Zu}$ den Gemeinderatswahlen vgl. ebd., S. 90-102. Zitat: StAnz Nr. 286 vom 7.12.1931. 
Raths mit starkem Beifall bedachten Ausführungen ${ }^{245}$ dokumentierten, dass die Partei scheinbar geschlossen den Rechtskurs Dingeldeys mittrug. Allerdings gab es vereinzelten Widerstand. Das Vorstandsmitglied des Stuttgarter Ortsvereins, Schlender, verließ nach langjähriger Mitgliedschaft „wegen des zutiefst illiberalen Verhaltens" Dingeldeys die Partei ${ }^{246}$.

Entgegen den ursprünglichen Absichten beschloss ein Vertretertag schließlich ein Wahlbündnis mit den württembergischen Volkskonservativen ${ }^{247}$, den abtrünnigen ehemaligen Deutschnationalen ${ }^{248}$. Mitte April veröffentlichte Rath eine Betrachtung zu den Wahlen ${ }^{249}$, in der er die Alternative aufzeigte, ob Württemberg fernerbin eine Ordnungszelle bleiben könne, oder aber die Entwicklung einer verhängnisvollen Ausgabenwirtschaft drohe, die anderwärts seit Jabren zu beobachten sei. Während seine Partei im Landtag eine Politik eiserner Sparsamkeit im Sinne der Regierung verfolgt habe, hätten Kommunisten, SPD, NSDAP und der Volksdienst nahezu einen Raubzug auf die staatlichen Kassen versucht. Ahnungsvoll gestand er jedoch ein, dass bei der verantwortungsvollen Haltung seiner Partei und der Regierung eine gewisse Hartherzigkeit unvermeidbar gewesen sei. Das Bestreben zur Vermeidung einer finanziellen Katastrophe habe naturgemäß wenig Befriedigung ausgelöst und kaum neue Freunde gebracht. Dennoch werde man an diesem Kurs festhalten.

Mitte April sprach Dingeldey in Stuttgart über die Reichspolitik, die seit Mitte 1931 voller Irrtümer verlaufen sei. Er bedauerte das Scheitern einer nationalen Front hinter Hindenburg und sprach Hitler die Fähigkeit ab, ein Volk zu einigen. Als Kostprobe seiner Wirtschaftspolitik beklagte er gänzlich unpassend die Notlage der ostdeutschen Großgrundbesitzer ${ }^{250}$.

Während einer schlecht besuchten Wahlversammlung in Crailsheim rühmte Hartmann die gute Politik seiner Partei. Ein zweiter Redner warnte vor einem Sieg des Sozialismus, den er durch Kommunisten und NSDAP vertreten sah und der das Ende bedeute. Er hoffte, dass in Württemberg kein radikalisierter Landtag gewählt werde und so von dort aus ein Gesundungsprozess einsetzen könne ${ }^{251}$. In einer

245 KB Nr. 26 vom 22.2.1932.

246 Zit. nach Richter, Die Deutsche Volkspartei (wie Anm. 1) S. 750.

247 FrGb Nr. 73 vom 30.3.1932.

$248 \mathrm{Zu}$ diesen Hans Peter Müller, Sammlungsversuche charaktervoller Konservativer. Die Volkskonservativen in Württemberg 1930-1932, in: ZWLG 64 (2005) S.339-354, zum Bündnis S. $348 \mathrm{f}$.

249 „Um was geht es bei den Landtagswahlen?“, Hohenloher Bote Nr. 87 vom 15.4.1932. Daraus das Folgende.

250 Hohenloher Bote Nr. 88 vom 16.4.1932.

251 FrGb Nr. 89 vom 18.4.1932. - Diese Hoffnung wurde dadurch genährt, dass bei den Reichspräsidentenwahlen im Frühjahr, auf die sich ja auch Rath und Dingeldey bezogen hatten, Hindenburg wiedergewählt wurde und der Kandidat Hitler nur eine „vergleichsweise schmale Basis“ in Württemberg erreichte. Vgl. dazu Schnabel, Württemberg (wie Anm. 3) S. 105-110, Zitat S. 110. 
Rede in Göppingen betonte der Landtagsabgeordnete Mayer, die Parteiarbeit sei ein steter Kampf gegen die Sozialdemokratie gewesen. Man werde sich gegen jede Untergrabung der staatlichen und kommunalen Finanzen stellen. Auch Keinath wandte sich dort gegen die SPD und betonte, mit allen nationalen Parteien kooperieren $\mathrm{zu}$ wollen ${ }^{252}$.

Während einer gemeinsamen Wahlversammlung mit den Volkskonservativen in Calw konstatierte Rath eine Reichsverdrossenheit, resultierend aus dem gegenwärtigen Parlamentarismus und der Ausgabenwirtschaft in Berlin sowie der Benachteiligung Württembergs auf verschiedenen Gebieten. In Kontrast dazu setzte er die im Lande herrschende Ordnung, die trotz drohender weiterer Einsparungen alternativlos sei, auch wenn man sich damit unbeliebt mache. Er präsentierte zudem ein Programm, das der Stärkung des Mittelstandes verpflichtet sei und appellierte abschließend an das staatsbürgerliche Pflichtgefübl im Kampf gegen die Unvernunft $t^{253}$.

In letzter Stunde war es gelungen, das Wahlbündnis mit den Volkskonservativen um die Wirtschaftspartei zu erweitern ${ }^{254}$. Zweifellos war diese Allianz nur eine Not- und Verlegenheitslösung, die durch den Widerspruch gekennzeichnet war, dass die DVP mit den Deutschnationalen koaliert hatte und nun mit deren volkskonservativen Gegnern zusammenging. So prognostizierte die DNVP in einem Aufruf, die Nationalliberalen würden als schwankendes Zwittergebilde ihre enttäuschten Wähler verlieren ${ }^{255}$.

Der Wahlausgang vom 24. April zeigte dann, dass die Haltung der DVP bei den Wählern keine Resonanz fand. Das Bündnis konnte nur etwa 1,5\% der Stimmen erreichen und blieb ohne Mandat ${ }^{256}$, während die NSDAP stärkste Partei im Lande wurde. Sie hatte wohl großenteils die früheren DVP-Wähler an sich gezogen, wie die „Württemberger Zeitung“ meinte. Der „Merkur“ sah in der grundstürzenden Wabl zu Recht eine Katastrophe der Volkspartei; sie sei zudem noch vom Pech der Wablarithmetik betroffen worden. Das Fazit des Blattes war klar und zutreffend: Die Führung der Partei [habe] in den letzten Jabren in Württemberg nicht mebr so überzengt, wie dies unter Stresemann der Fall war ${ }^{257}$.

Anfang Mai kommentierte Rath vor dem geschäftsführenden Landesausschuss die Wahlen. Er gestand sowohl manche Unterlassungssünde als auch die Tatsache ein, dass das schmerzliche Ergebnis hauptsächlich auf den Einbruch der NSDAP in

252 Merkur vom 19.4.1932.

253 Calwer Tagblatt vom 18.4.1932. Für die Kopie des Artikels sei Herrn Dr. K. Mayer vom Stadtarchiv Calw herzlich gedankt.

254 KB Nr. 91 vom 20.4.1932.

255 KB Nr. 90 vom 19.4.1932.

256 Vgl. Schnabel, Württemberg (wie Anm.3) S. 118, zu den Wahlen insgesamt S. 110122.

257 Wahlkommentare im KB Nr.96 vom 26.4.1932. 
weite Kreise der Partei zurückzuführen sei. Zudem habe auch eine Abwanderung zur DNVP stattgefunden.

Schließlich bedauerte er, dass nur 581 Stimmen zur Erreichung eines Mandats gefehlt hätten ${ }^{258}$. In völliger Fehleinschätzung erwartete er einen Rückgang der Hitlerbewegung und sah eine Umbildung des Parteiwesens voraus. Man dürfe daher nicht verzweifeln; unbedingt müsse die Parteiorganisation erhalten bleiben. Zu seinen vom Ausschuss mit Zustimmung aufgenommenen Ausführungen, zu denen ein erstaunlicher Zukunftsoptimismus trat, gehörte die Absage an die vom Geist Hugenbergs beherrschte DNVP und die Betonung fortbestehender guter Beziehungen zu den Volkskonservativen und der Wirtschaftspartei ${ }^{259}$.

\section{Niedergang und Ende 1932/1933}

Nach den Wahlen kam es in Württemberg nicht mehr zu einer verfassungsgemäßen Regierung. Die bürgerlichen Parteien weigerten sich, der NSDAP die zentralen Ministerien zu überlassen - und in einer fatalen Borniertheit lehnten sie auch eine Zusammenarbeit mit der SPD ab. So blieb das Kabinett Bolz, natürlich ohne den vormaligen Staatsrat Rath, als geschäftsführende Regierung im Amt.

Ende Juni beschäftigte sich der geschäftsführende Landesausschuss der Volkspartei mit den kommenden Reichstagswahlen ${ }^{260}$. Keinaths Bericht über die gescheiterten Sammlungsversuche der Mittelparteien veranlasste die Delegierten zur Kritik. Die Reichsleitung habe zu lange gezögert und zu viel Zeit mit Verhandeln verloren. Im Zentralvorstand sollten die Vertreter Württembergs für ein selbständiges Vorgeben plädieren. Man erstrebe einen Wablkreisverband mit Baden sowie eine Listenverbindung mit anderen Rechtsparteien ${ }^{261}$.

Dingeldey und Hugenberg einigten sich auf ein „technisches“ Abkommen ihrer Parteien, das die Selbständigkeit der DVP bewahrte ${ }^{262}$. Ein Wahlflugblatt der Reichspartei betonte die schwere Schuld der Parteiberrschaft, forderte zur Besonnenheit auf und versprach unter Berufung auf Stresemann den Kampf um Freibeit und Recht gegen die vormaligen Kriegsgegner zu führen ${ }^{263}$. In deren Wahlaufruf wurde die Richtigkeit der Parole für Hindenburg und gegen Brüning betont; gegenüber dem Kanzler von Papen bleibe man ungebunden und abwartend, erwarte jedoch eine Verfassungsreform sowie die starke Führung durch die Reichsspitze.

${ }^{258}$ Die DVP und ihre Verbündeten fochten die Sitzverteilung beim Staatsgerichtshof an, FrGb Nr. 128 vom 4.6.1932. Der Schritt blieb jedoch erfolglos.

259 KB Nr. 105 vom 7.5.1932.

260 Nach dem Rücktritt Brünings am 30. Mai 1932 hatte der neue Kanzler von Papen den Reichstag aufgelöst, die Neuwahlen wurden auf den 31.7. terminiert.

${ }^{261}$ KB Nr. 144 vom 23.6.1932.

${ }^{262}$ Vgl. Richter, Die Deutsche Volkspartei (wie Anm. 1) S. $762 \mathrm{f}$.

263 „Nicht leidenschaftliche Demonstrationen ...", Stadtarchiv Stuttgart, Nachlass Kimmich/Schmalzried, 14/4. 
Die allgemeine Lage verbiete alle demagogischen Versprechungen; das Streben gelte der nationalen Volksgemeinschaft ${ }^{264}$.

Der wiederum als württembergischer Spitzenkandidat nominierte Keinath ${ }^{265}$ forderte während einer Stuttgarter Wahlversammlung autoritative Elemente für die zu ändernde Reichsverfassung. Die den Wählern gebotene Alternative lautete für ihn, entweder Sieg des Sozialismus aller Schattierungen und damit der Untergang, oder aber ein Votum für die Privatwirtschaft und damit die Volkswohlfabrt ${ }^{266}$.

In dem sozusagen auf ,Sparflamme، geführten Wahlkampf der württembergischen DVP fehlten nach dem Desaster bei den Landtagswahlen sowohl der Elan als auch ausreichende Geldmittel ${ }^{267}$. Eine Wahlanzeige pries die DVP als Partei der Vernunft, während die Massenparteien durch Radikalismus und unerfüllbare Versprechungen geprägt seien, die schließlich zum Bolschewismus führten ${ }^{268}$. Eine weitere Anzeige wandte sich an das klassische Wählerpotenzial - Angestellte, Beamte, Handwerker und Mittelständler. In deren Interesse sei man Gegner jeder Sozialisierung und Hort des Privateigentums, stehe für strengste Sparsamkeit und gegen falsche Stenerpolitik und Korruption ${ }^{269}$ - die NSDAP wurde so bestenfalls indirekt angesprochen.

Diese Appelle konnten jedoch nicht überzeugen. Das Wahlergebnis war erneut deprimierend; der Landesverband blieb wiederum ohne Mandat. In einer Wahlbetrachtung hieß es angesichts des Verlustes von über 6.000 Stimmen gegenüber der Landtagswahl zutreffend, die Partei habe ibren Auflösungsprozeß fortgesetzt ${ }^{270}$. Dies galt auch für die Reichs-DVP, die nur noch sieben Sitze erreichte und damit Dingeldeys hektisches Lavieren ad absurdum führte 271 . Die NSDAP war mit 230 Mandaten zur stärksten Partei im Reichstag geworden.

Kanzler von Papen löste nach einer vernichtenden Reichstagsniederlage im September - nur DNVP und DVP standen an seiner Seite -, das Parlament auf. Erst Mitte Oktober trat der Vertretertag der DVP wieder auf den Plan, um sich mit dem neuen, zum 6. November ausgeschrieben Urnengang zu beschäftigen. Rath bezeichnete dort offenbar ohne Selbstzweifel das Handeln seiner Partei während der letzten Jahre als richtig. Damit meinte er die von Dingeldey betriebene Lösung von Brüning und die trene Gefolgschaft zu Hindenburg. Er bedauerte, dass es nicht

264 Der Aufruf ebd.

265 FrGb Nr. 162 vom 14.7.1932.

266 Hohenloher Bote Nr.176 vom 30.7.1932. Keinath billigte dort auch den Staatsstreich gegen Preußen, d.h. die Absetzung der Regierung Braun.

267 Zum Geldmangel Richter, Die Deutsche Volkspartei (wie Anm.1) S.765 mit Anm. 32 .

268 KB Nr. 175 vom 29.7.1932 (z.T. in Fettdruck).

269 HT Nr. 176 vom 30.7.1932 (z.T. in Fettdruck).

270 KB Nr. 177 vom 1.8.1932.

271 Zum Wahlkampf auf Reichsebene Richter, Die Deutsche Volkspartei (wie Anm. 1) S. 760-768. SchnabeL, Württemberg (wie Anm.3) erwähnt wie auch in seinen früheren und nachfolgenden Wahlbetrachtungen die DVP kaum.

Zeitschrift für Württembergische Landesgeschichte 74 (2015), S. 249-296.

(C) Kommission für geschichtliche Landeskunde in Baden-Württemberg und Württembergischer Geschichts- und Altertumsverein e.V.

ISSN 0044-3786 
gelungen sei, zu einer einheitlichen Hindenburg-Front zu gelangen. Für die kommende Wahl sei die Entscheidung einfach. Es gelte, sich für oder gegen die vom Präsidenten etablierte Regierung Papens zu entscheiden. Seine Partei habe sich sofort an deren Seite gestellt und werte deren Programm als befreiende Tat. Diese Einschätzung fand Zustimmung, gleichzeitig wurde Keinath erneut zur Kandidatur aufgefordert und ihm Dank und Anerkennung gezollt ${ }^{272}$.

Diese Haltung war praktisch identisch mit dem Kurs der Reichspartei. Deren Wahlaufruf forderte für die Regierung, die Beauftragten Hindenburgs, die Möglichkeit zur Arbeit, drohten doch durch den Macbtdïnkel zerstörerischer Parteien die letzten Hoffnungen zu scheitern ${ }^{273}$. Teilweise verändert und ergänzt wurde der Aufruf für eine Anzeige benutzt, die Hindenburgs göttliche (n) Auftrag in scharfen Kontrast zu Hitler setzte. Dieser erstrebe die Diktatur seiner Partei und habe sich mit den Übeltäter $(n)$ von Beuthen solidarisiert ${ }^{274}$. Eine wohl landesweit geschaltete Anzeige verbreitete wiederum einen erstaunlichen Optimismus. Sie sprach vom neuen Aufstieg der Partei, gekennzeichnet durch neue Beitritte, Opferwilligkeit der Mitglieder und Vertranen in die Zukunft. Nachdem man seit über 60 Jahren unentbebrlicher Faktor der deutschen Geschichte gewesen sei, trete man nun mit Hindenburg, dem man stets treu zur Seite gestanden habe, zur Rettung Deutschlands $\mathrm{an}^{275}$.

Insgesamt wurde der wiederum im Zeichen finanzieller Probleme zu bestreitende Wahlkampf erneut nur in recht zurückhaltender Weise geführt ${ }^{276}$. Obwohl Keinath ohne Mandat blieb, konnte der Landesverband gegenüber den Juliwahlen doch einen Stimmenzuwachs von über 6000 erzielen und ein Kommentar sah die Partei wieder im Aufstieg begriffen ${ }^{277}$. Auch die Reichspartei hatte ihre Mandate auf elf erhöhen können, während die NSDAP einen bemerkenswerten Rückschlag $\operatorname{erlitt}^{278}$.

In dem „Intrigenwirrwarr" nach den Novemberwahlen (Helmut Heiber) konnte der optimistische Dingeldey mit seiner auf dem Niveau einer Splitterpartei verharrenden DVP nur als Statist wirken. Seine Hoffnung, nach dem Rücktritt des von ihm unterstützten Kanzlers von Schleicher Ende Januar 1933 nun mit der DVP den Linksflügel der „Kampffront Schwarz-Weiß-Rot“ Hugenbergs besetzen zu können, scheiterte. So blieb ihm nur ein mit dem Christlich-Sozialen Volksdienst, der Deutschen Bauernpartei und der Deutsch-Hannoverschen Partei geschlossenes

272 KB Nr. 244 vom 18.10.1932.

273 KB Nr. 248 vom 22.10.1932.

274 HT Nr. 259 vom 4.11.1932. - Im schlesischen Potempa bei Beuthen hatten SA-Leute einen kommunistischen Arbeiter bestialisch ermordet.

275 KB Nr. 259 vom 4.11.1932.

276 Wahlbetrachtung des Merkurs, zit. nach StAnz Nr. 262 vom 8.11.1932.

277 KB Nr. 261 vom 7.11.1932.

278 Vgl. Richter, Die Deutsche Volkspartei (wie Anm.1) S. 776-782, zur Finanznot S. $778 \mathrm{f}$. 
technisches Abkommen, das Reststimmen für die zum 5. März 1933 ausgeschriebenen neuen Reichstagswahlen sichern sollte ${ }^{279}$.

Nach Hitlers Ernennung zum Reichskanzler am 30. Januar 1933 stellte die „Nationalliberale Korrespondenz" bedauernd fest, in dessen Kabinett fehlten Vertreter der gemäßigten Rechten und solche der mittleren politischen Linie. Es stelle daher keine wirkliche nationale Konzentration dar ${ }^{280}$. Etwas später betonte Dingeldey auf einer Sitzung des Reichsausschusses, man werde der Regierung nicht mit grundsätzlicher Opposition begegnen, sondern sie an ihren Taten messen ${ }^{281}$.

Während der Vorsitzende der Stuttgarter Ortsgruppe, Alfred Krämer, der dann zum Spitzenkandidaten nominiert wurde, Dingeldey aufgefordert hatte, „vorerst

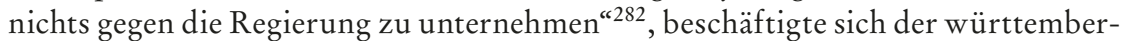
gische Landesausschuss am 9. Februar mit der für Rath überaus ernste $(n)$ politische (n) Lage. Die Parteivertreter stellten sich einmütig hinter die Reichsführung und hofften auf den Zusammenschluß aller Parteien zwischen NSDAP und Zentrum. Komme dieser nicht zustande, werde die DVP selbständig handeln. Dann träten die vorsorglich ausgehandelten wabltechnischen Vereinbarungen in Wir$\mathrm{kung}^{283}$.

Anfang März zeigte sich, dass man innerhalb der Landespartei nicht einig war. Mitglieder der Ortsgruppe Esslingen hatten einen Aufruf veröffentlicht, der zur Wahl der Kampffront aufrief. Diesen Schritt bezeichnete der geschäftsführende Ausschuss als gegen Satzungen und Parteidisziplin verstoßend; die Initiatoren hätten sich außerbalb der Parteiorganisation gestellt und Konsequenzen zu erwar$\operatorname{ten}^{284}$. Auf den mit wenig Einsatz geführten Wahlkampf musste dieses Ereignis verheerend wirken. In Anzeigen wurde etwa beklagt, dass die um die nationale Befreiung verdiente Partei nicht aus einer nationalen Front ausgeschlossen werden dürfe. Gleichzeitig folgten Appelle an die Vernunft: Man stehe für die unantastbare Bürgerfreibeit, wende sich gegen immer neue Wablen und beschwor die eigene nationale und liberale Weltanschaunng als Gegengewicht zu den Machtgelüsten egoistischer Parteipolitiker ${ }^{285}$. Schließlich empfahl man sich als Partei der selbständig denkenden Menschen ${ }^{286}$.

Mit diesem Tenor argumentierte auch Rath. Er sah für die DVP eine Aufwärtsbewegung und sprach sich gegen Stimmen in der Partei aus, die für ein Aufgehen im sog. nat. Block plädierten. Während die NSDAP, die das staatliche System jahrelang berannt habe, inzwischen weitgehend im Besitze der Macht sei, stelle sich die

\footnotetext{
279 Vgl. dazu Richter, Die Deutsche Volkspartei (wie Anm. 1) S. 794.

280 Zit. nach KB Nr. 27 vom 2.2.1933.

281 KB Nr. 31 vom 7.2.1933.

282 Zit. nach Richter, Die Deutsche Volkspartei (wie Anm. 1) S. 793.

283 StAnz Nr. 34 vom 10.2.1933.

284 HT Nr. 52 vom 3.3.1933.

285 KB Nr. 53 vom 4.3.1933 (z. T. in Fettdruck).

286 Hohenloher Bote Nr. 53 vom 4.3.1933.
} 
Frage, ob wir überhaupt noch in einem Rechtsstaat leben, denn Recht u. Gerechtigkeit seien immer in Gefabr, wenn eine extreme Richtung regiere. Allerdings gestand er zu, dass die derzeitigen Verhältnisse diktatorische Maßnabmen erforderten, die jedoch keine Einzelrechte oder die Stellung der Länder beeinträchtigen dürften. Während er Bedenken gegen die Wirtschaftspolitik Hugenbergs äußerte, sah er die Aufgabe der DVP darin, für einen Mittelweg zu sorgen und einem $\mathrm{Ge}^{-}$ wissenszwang wie in Italien entgegenzutreten. Man wolle gegenüber der neuen Regierung Verständnis aufbringen, dabei aber am Rechtsstaat festhalten. Daher sei das eigenständige Auftreten der Partei absolut geboten ${ }^{287}$.

Angesichts einer sich ausbreitenden, durch den wohl inszenierten Reichstagsbrand noch zusätzlich angeheizten Massenhysterie konnten die Argumente der Partei, die wiederum ohne Mandat blieb, nicht überzeugen. So erlebten die württembergischen Nationalliberalen mit nur noch knapp 11.000 Stimmen, ein Verlust von etwa 8.500 gegenüber den Novemberwahlen ${ }^{288}$, ihr endgültiges Waterloo. In einem Kommentar des „Merkurs“ wurde konstatiert, die Massen hätten sich bei starker Wahlbeteiligung von den Liberalen ab- und vor allem der NSDAP zugewandt. Gleichzeitig sei die DVP trotz ihrer Bereitschaft zur Mitarbeit in Hugenbergs Kampffront dort unerwünscht gewesen ${ }^{289}$. Auch die Reichspartei erreichte nur noch zwei Sitze, darunter Dingeldey, der auch an erster Stelle auf dem württembergischen Wahlzettel stand ${ }^{290}$.

Nachdem der Prozess der Zerstörung des demokratischen Staatswesens bereits in vollem Gang war und ein „wahrer Massenexodus“ aus der DVP einsetzte ${ }^{291}$, konstatierte Anfang April die Berliner Parteiführung, einer gewaltigen nationalen Volksbewegung sei es gelungen, das Hindernis deutscher Wiedergenesung hinwegzuräumen. Die Unterstützung Hitlers galt ihr als selbstverständliche Pflicht. Nach der Erschütterung der alten bürgerlichen Parteiformen erfordere ein neuer Geist auch neue Formen ${ }^{292}$. Über Wochen suchte Dingeldey nach jenen Formen zur Erhaltung des Nationalliberalismus. Nachdem er am 4. Juli die Auflösungserklärung der DVP formuliert hatte, trat er Ende September als Hospitant zur NSDAP ${ }^{293}$.

Ungeachtet dieser Bemühungen zogen die Württemberger die realistische Konsequenz aus den gegebenen Verhältnissen in eigener Regie. Die letztmalig tagende

287 Undatiertes Redemanuskript Raths: „Die Aufgaben der Deutschen Volkspartei nach dem 5. März“, Stadtarchiv Tübingen A 10/N 93/99.

288 Statistisches Handbuch für Württemberg 1927-1935, Stuttgart 1937, S. 311.

289 Nach StAnz Nr. 55 vom 7.3.1933.

290 Vgl. Hohenloher Bote Nr. 47 vom 25.2. 1933. - Zu den Wahlen im Reich und ihren Hintergründen Richter, Die Deutsche Volkspartei (wie Anm.1) S.792-800. Schnabel, Württemberg (wie Anm.3) der wiederum die DVP kaum beachtet, wies darauf hin, dass der Wahlkampf der Bürgerlichen und der SPD im Gegensatz zum Reich „nicht entscheidend“ behindert wurde, ebd., S. 167.

291 Richter, Die Deutsche Volkspartei (wie Anm. 1) S. 803.

292 KB Nr. 79 vom 4.4.1933.

${ }^{293}$ Zum Auflösungsprozess Richter, Die Deutsche Volkspartei (wie Anm. 1) S. 801-820.

Zeitschrift für Württembergische Landesgeschichte 74 (2015), S. 249-296.

(C) Kommission für geschichtliche Landeskunde in Baden-Württemberg und Württembergischer Geschichts- und Altertumsverein e.V.

ISSN 0044-3786 
Vertreterversammlung löste Mitte Mai den Landesverband auf. Sie erklärte, keine Möglichkeit mehr zu sehen, ihre Organisation zu erbalten. Dieser Schritt erfolge im Bewusstsein, für eine gute Sache gestritten zu haben, hätten doch alle Bemühungen stets der Größe und Macht Deutschlands, der Ausmerzung marxistischer Ideen und der Bildung einer wabren Volksgemeinschaft gegolten. Die Nationalliberalen verließen die politische Bühne mit der Erwartung, der neuen Regierung möge es gelingen, auf neuen Wegen Deutschland einer glücklichen Zukunft entgegenzufübren ${ }^{294}$.

\section{Schlussbetrachtungen}

Die in Württemberg verspätet - nach einem konfusen Neben- und Gegeneinander-Agieren und nur durch ,Geburtshilfe‘ der Reichspartei - in die politische Arena tretende DVP war von Anfang an mit einer ganzen Reihe von Problemen konfrontiert. Mit der DDP und den Deutschnationalen, später dann auch den neuen Parteien, konkurrierte man um die bürgerliche Wählerschaft. Während das Wahlrecht die kleine Partei benachteiligte, kamen interne Probleme hinzu. Der Parteiaufbau verlief schleppend, ablesbar etwa am anfangs häufigen Wechsel der Parteisekretäre und der erstaunlich späten Gründung der Arbeitsgemeinschaften. Hinzu trat die späte ,Wiederentdeckung ' der „Schwabenwarte“ als Parteiblatt; allerdings behandelte der „Merkur“ die DVP wohlwollend ${ }^{295}$. Für den Chronisten kommt schließlich hinzu, dass eigentliche Parteiakten fehlen ${ }^{296}$ und die „Schwabenwarte“ nur äußerst lückenhaft überliefert ist. Insofern blieben möglicherweise parteiinterne Vorgänge da und dort im Dunkel.

In der konstruktiven und staatstragenden Rolle der kleinen Partei als „Zünglein an der Waage" in der württembergischen Landespolitik, die schließlich zum Eintritt in die Regierung führte, sahen die drei Parteiführer ihre eigentliche Aufgabe. Diese Haltung wurde von den Mitgliedern und Wählern bis zum Fiasko von 1932 mitgetragen. Egelhaaf und Bickes gebührt das Verdienst, den deutschnationalen Charakter der Bürgerpartei früh erkannt und daraus die - ihr liberales Grundverständnis dokumentierende - Konsequenz gezogen zu haben. Beide trugen zunächst Stresemanns ,alten Kurs' mit, um sich dann seiner Wandlung zum realistischen Staatsmann anzuschließen. Letzteres galt auch für Rath.

294 StAnz Nr. 111 vom 15.5.1933. Die Feststellung, die Auflösung der württembergischen DVP habe im Staatsanzeiger keine Erwähnung gefunden - so SchnA beL, Württemberg (wie Anm. 3) S. 672, Anm. 9 - ist also unzutreffend.

295 Auch der Staatsanzeiger und Provinzblätter wie etwa der Kocherbote berichteten über die Parteiaktivitäten relativ ausführlich.

296 Allerdings besitzt das Stadtarchiv Tübingen eine Materialsammlung zu Johannes Rath, aus der mir dankenswerterweise Einzelstücke kopiert wurden.

Zeitschrift für Württembergische Landesgeschichte 74 (2015), S. 249-296.

(C) Kommission für geschichtliche Landeskunde in Baden-Württemberg und Württembergischer Geschichts- und Altertumsverein e.V.

ISSN 0044-3786 
So standen die drei Vorsitzenden für die den Landesverband im Unterschied zu vielen anderen Regionalgliederungen kennzeichnende Treue und Bewunderung ihres Parteiführers.

Ein weiteres zentrales Ergebnis dieser Untersuchung stellt der Befund dar, dass die württembergische DVP ganz dezidiert nicht als Interessenvertretung der Großindustrie bzw. des großen Geldes agierte. Vielmehr war der Landesverband bemüht, für einen sozialen Ausgleich und vor allem mittelständische Interessen zu wirken. Die Wirtschafts- und Staatskrise sollte dieser Politik - und den Grundsätzen Stresemanns - dann die Basis entziehen. Die desorientierte und sich radikalisierende bürgerliche Mitte, jedenfalls auf evangelischer Seite, orientierte sich nach rechts und stieß schließlich in Scharen zu den Nationalsozialisten, deren wahrer Charakter von den bürgerlichen Parteien nie wirklich erkannt wurde. Während die württembergischen Nationalliberalen die NSDAP durchaus skeptisch beurteilten, versuchten sie 1930 mit dem gegen den Willen der Reichspartei initiierten liberalen Wahlbündnis, sich gegen die erkennbar heraufziehende Krise zu stemmen. Nach dessen Scheitern waren sie letztlich alternativlos der Rechtswendung des überforderten und lavierenden Dingeldey ausgeliefert und verloren so - wie die Reichspartei - zusätzlich an Glaubwürdigkeit. Auch Raths Konzept einer württembergischen „Ordnungszelle“ wurde letztlich von den Wählern nur als Sparappell wahrgenommen.

Mit der ,Ausbootung' des um die Partei verdienten Bickes 1930 wurden bereits Krisensymptome im zuvor weitgehend geschlossenen Landesverband erkennbar. Nach der verheerenden Niederlage bei der Landtagswahl 1932 fielen die württembergischen Nationalliberalen sozusagen in eine Art Schockstarre. Diese wird insofern nachvollziehbar, als sie 1930 und erneut 1932 erfahren mussten, dass ihre selbst initiierten Parteibündnisse nach links und nach rechts gescheitert waren, wirkliche politische Optionen also fehlten.

Dementsprechend versäumten sie es 1932, etwa durch einen gut organisierten Parteitag ihren Lebenswillen nach außen zu dokumentieren. Auch wenn ein solcher sicherlich keine Wende gebracht hätte, wäre es ein Zeichen des Sich-Aufbäumens gewesen. So wurden die anschließenden Reichstagswahlkämpfe sozusagen auf Sparflamme geführt und bestenfalls Zweckoptimismus artikuliert. Die Resignation in den schmelzenden Reihen der Partei und ihrer Wähler war unübersehbar. Sparappelle und solche an die Vernunft sowie die Berufung auf Hindenburg blieben wirkungslos. Auch der zuvor so vielfach aktive Rath setzte keine wirklichen Akzente mehr. So war die Auflösung des Landesverbandes im Mai 1933 nur konsequent $^{297}$. Die dabei geäußerte Gewissheit, für eine gute Sache gestritten zu haben,

297 Dies fand auch der „Merkur/Kronik“ (Nr. 113 vom 16.5.1933), der den württembergischen Parteiführern Anerkennung und Dank für ihre vaterländische und uneigennützige Arbeit zollte und dabei konstatierte, die Partei habe in der Republik nie die im Kaiserreich innegehabte Bedeutung erreichen können. 
war durchaus zutreffend. Allerdings war dieser Einsatz spätestens seit den Landtagswahlen von 1932 letztlich aussichtslos geworden. 